\title{
EVALUANDO REFORMAS TRIBUTARIAS EN CHILE CON UN MODELO CGE*
}

\author{
EVALUATING TAX REFORMS IN CHILE WITH A CGE MODEL
}

\author{
Cristian Mardones Poblete**
}

\begin{abstract}
Resumen
Este trabajo realiza una evaluación cuantitativa de posibles reformas al sistema tributario chileno. Las simulaciones se basan en un modelo de equilibrio general computable, dinámico, recursivo, calibrado, con la matriz insumo-producto 2003. Para lo anterior se consideran rebajas en la tasa efectiva del impuesto al valor agregado y aumentos de la tasa efectiva del impuesto a la renta del quintil más rico en $20 \%$ y $40 \%$, respectivamente. Los resultados de las variables agregadas del modelo son traspasados a microdatos para analizar los efectos desagregados. Finalmente, se concluye que bajar el IVA y subir el impuesto a la renta generaría sólo mejoras acotadas en la pobreza y distribución del ingreso.
\end{abstract}

Palabras clave: Reforma tributaria, Distribución del ingreso, CGE, Microsimulaciones.

\begin{abstract}
This paper makes a quantitative assessment of possible reforms to the Chilean tax system. The simulations are based on a recursive dynamic computable general equilibrium model that is calibrated with the input-output matrix 2003. For each scenario is considered a cut effective rate of value added tax and an increase in the richest quintile's effective rate of income tax by $20 \%$ or $40 \%$ respectively. The results of the model are transferred to micro data to analyze the effects disaggregated. Finally, I conclude that cutting the VAT and raising income tax only would generate bounded improvements in poverty and income distribution.
\end{abstract}

Key words: Tax reform, Income inequality, CGE, Microsimulation.

JEL Classification: D63, E62, H22, H24, H30.

* El autor agradece al editor, Rómulo Chumacero, y los valiosos comentarios y observaciones ofrecidos por un árbitro de Estudios de Economía, los cuales ayudaron a mejorar significativamente este trabajo. También se agradece especialmente a Raúl O’Ryan (PNUD y Universidad de Chile) y Mauricio Pereira (CEPAL).

** Profesor Asistente, Departamento de Ingeniería Industrial, Universidad de Concepción. Edmundo Larenas 215, Cuarto Piso, Concepción - Chile. Tel.: +56 (41) 2203614. E-mail: crismardones@udec.cl 


\section{INTRODUCCIÓN}

Las reformas al sistema tributario generan efectos sustanciales que repercuten en toda la economía de un país, ya que cambian los precios relativos de bienes y factores productivos alterando las decisiones de los agentes económicos. En consecuencia, una evaluación cuantitativa de una reforma tributaria en la economía que considere los impactos económicos directos e indirectos de tal medida debe ser analizada preferentemente en el marco de un equilibrio general.

En Chile las dos principales fuentes de recaudación tributaria son el impuesto al valor agregado (IVA) e impuesto a la renta. El primero genera aproximadamente la mitad de la recaudación, pero su carga es más elevada para las familias de menores ingresos, mientras el segundo genera aproximadamente un cuarto de la recaudación con una tasa efectiva de sólo 4,8\% del PIB (promedio años 2000 a 2009). La baja recaudación del impuesto a la renta se explicaría porque una parte significativa de la población está exenta debido a sus bajos ingresos, exenciones y por la evasión.

Estudios previos han sugerido propuestas de reformas tributarias y otros las han evaluado en el marco de equilibrio parcial. En el marco de las propuestas se pueden mencionar los trabajos de Fontaine y Vergara (1997), quienes sugirieron mantener la tasa del IVA, eliminar algunos impuestos específicos, reducir gradualmente la tasa general de aranceles y generar una reforma global del impuesto a la renta, en la cual la tasa marginal máxima del impuesto a las rentas personales se igualara con el impuesto a las utilidades retiradas en una tasa de 20\%; Serra (2000) planteó que para eliminar la complejidad del sistema impositivo chileno se sustituyera el impuesto al ingreso por una estructura impositiva que consistía en un impuesto de tasa única al flujo de caja de las empresas y un impuesto al trabajo con una tasa máxima bajo la tasa al flujo de caja; Agostini (2008) propuso disminuir el número de tramos del impuesto global complementario, reducir las tasas marginales, eliminar la mayoría de las exenciones, y aumentar levemente la tasa del impuesto a las utilidades de las empresas, lo anterior con el objetivo de reducir los incentivos a evadir o eludir impuestos, y facilitar la administración del sistema tributario. En el caso de estudios que han evaluado reformas tributarias en el marco de equilibrio parcial, podemos citar el trabajo de Engel et al. (1999), quienes concluyen que cambios "drásticos" de la estructura tributaria no alteran la distribución del ingreso, por lo que sugieren incrementar los impuestos que recaudan mucho (IVA) y reducir las tasas marginales más altas del impuesto a la renta por ser distorsionadoras, costosas de administrar y recaudar relativamente poco; y Cantallops et al. (2007), evalúan el potencial distributivo del sistema tributario chileno simulando reformas tributarias que dan mayor preponderancia al impuesto progresivo a la renta reduciendo la participación del IVA; sus resultados sugieren que estos cambios a la estructura tributaria podrían tener impactos significativos sobre la distribución del ingreso.

Considerando la importancia en la recaudación del impuesto a la renta y el IVA, así como también la regresividad y progresividad de la carga tributaria de ambos, esta investigación propone evaluar diversas simulaciones de cambios en la estructura impositiva de Chile mediante un modelo de equilibrio general computable (CGE), calibrado con los datos de una Matriz de Contabilidad Social (SAM) elaborada a partir de la información de la Matriz de InsumoProducto chilena del año 2003, datos de la encuesta CASEN 2003, Encuesta 
de Presupuestos Familiares y carga tributaria para el año 2003 por quintiles de ingreso obtenida del estudio de Cantallops et al. (2007) ${ }^{1}$. Específicamente se consideran diversos escenarios tributarios examinando sus efectos en el producto de la economía, sectoriales, balance fiscal, mercado de factores, ingreso de los agentes económicos, pobreza y en la distribución del ingreso.

Específicamente, los escenarios contrafactuales generados con el modelo corresponden a una rebaja de $10 \%$ y $20 \%$ en la tasa del IVA, un aumento del impuesto a la renta del quintil más rico de la población en $20 \%$ y $40 \%$, y una reducción del IVA en $10 \%$ y $20 \%$, pero compensando la recaudación fiscal con un aumento del $20 \%$ y $40 \%$ en la tasa efectiva de impuesto a la renta del quintil más rico de la población ${ }^{2}$. Estas simulaciones se implementan en el modelo como una modificación de las tasas ad valorem de estos impuestos a través de incrementos o disminuciones en las tasas efectivas. Cabe señalar que no es factible con este tipo de modelación tratar de cuantificar efectos de cambios complejos con distintos tramos de impuestos o de variación en las tasas marginales. Además, el análisis implícitamente considera que no existe una modificación en el comportamiento de los agentes relativo a la evasión o bien que la variación de las tasas efectivas simuladas son netas de evasión.

Los principales resultados de estas simulaciones son intuitivos, pero existen otros difíciles de haber identificado sin un análisis de equilibrio general. Podemos mencionar entre estos últimos que las rebajas del IVA elevan los salarios promedio en el horizonte modelado, en especial se incrementan porcentualmente más aquellos con menor nivel de calificación. Los escenarios que elevan el impuesto a la renta reducen los salarios, porcentualmente más aquellos menos calificados. Los escenarios que bajan el IVA pero elevan el impuesto a la renta también incrementan los salarios, pero con un impacto menor y más homogéneo entre niveles de calificación. Otros resultados poco intuitivos se obtienen al traspasar los resultados en las variables agregadas del modelo a microdatos, concluyéndose que estas reformas tributarias a pesar de ser bastante drásticas sólo tienen espacio para modificar marginalmente la distribución del ingreso de las familias, y que los mejores resultados son generados con la simultánea reducción del IVA y aumento del impuesto a la renta. Además, las reformas que generan la mayor reducción de la pobreza son la rebaja de un $20 \%$ en el IVA, y luego la rebaja de $20 \%$ en el IVA compensada por el aumento del impuesto a la renta en $40 \%$ del quintil más rico.

El documento se organiza de la siguiente manera. Luego de esta introducción se presenta una descripción del sistema tributario chileno junto con la presentación de información relativa a la recaudación de los distintos impuestos, para luego en la tercera sección hacer una breve revisión de literatura sobre cambios en la estructura tributaria y la modelación de equilibrio general. En la cuarta sección se presentan los datos y fuentes de información con la cual se elabora una matriz de contabilidad social de la economía chilena que permite

$\overline{1}$ Este estudio utiliza una definición más amplia de ingreso que estudios previos al incorporar la participación de los hogares en las utilidades retenidas de las empresas.

2 El impuesto a la renta sube el doble del porcentaje de la rebaja en el IVA e impuestos específicos para evitar la caída en la recaudación fiscal, aun cuando la compensación no es exacta. 
la calibración del modelo de equilibrio general computable dinámico utilizado. En la quinta sección se describe el modelo y sus limitaciones. En la sexta sección se realizan seis simulaciones de reformas en la estructura impositiva y se contrastan los resultados con los del escenario base. Finalmente, se presentan las principales conclusiones que pueden servir para la toma de decisiones en política tributaria.

\section{El SISTEMA TRIBUTARIO CHILENO}

A continuación se realiza una descripción del sistema tributario chileno, considerando la recaudación de los distintos tipos de impuestos, la estructura impositiva y carga tributaria según nivel de ingreso.

\section{Recaudación del Sistema Tributario Chileno}

En el período 2000 a 2009 la recaudación total del sistema tributario ascendió a un 16,7\% del PIB. La recaudación se concentra principalmente en el impuesto al valor agregado el cual recauda un $48,4 \%$, el impuesto a la renta recauda un $28,4 \%$ del total y el impuesto a productos específicos un 10,4\%. En la Figura 1 se puede observar en forma detallada la participación de cada impuesto sobre el total recaudado.

\section{Descripción del Sistema Tributario Chileno}

A continuación se presenta un breve resumen de los principales impuestos pagados por las personas en Chile siguiendo la revisión de Serra (2000) con el fin de establecer la situación base para en una etapa posterior poder evaluar algunas posibles reformas tributarias.

Los consumidores de bienes y servicios finales pagan el Impuesto al Valor Agregado (IVA), el cual tiene una tasa de 19\%, pero este tributo no es aplicado uniformemente a todos los bienes y servicios. Las exportaciones están gravadas con tasa cero, se estima que la tasa para la construcción de viviendas es cero (ya que existe un crédito de $65 \%$ del débito que generan la venta de inmuebles residenciales), algunas otras actividades exentas de pagar IVA son el transporte de pasajeros, seguros de vida, educación, parcialmente la salud y los intereses ${ }^{3}$, en estos casos los prestadores no recuperan el IVA de los insumos. Existen algunos Impuestos Específicos los cuales se aplican en forma adicional al IVA sobre las transacciones de ciertos productos, como es el caso de las bebidas, tabacos y los combustibles.

Las empresas pagan el llamado Impuesto de Primera Categoría que grava las utilidades devengadas con una tasa del $17 \% \%^{4}$, este impuesto es un crédito para el impuesto personal de los dueños de empresas residentes en el país o

3 Aun cuando los intereses están exentos de IVA, las operaciones de crédito pagan el denominado impuesto al crédito.

4 Un aumento temporal del impuesto a la renta se ha introducido para ayudar a financiar la reconstrucción luego del terremoto que afectó al país en febrero de 2010. 
FIGURA 1

INGRESOS TRIBUTARIOS COMO PORCENTAJE DEL TOTAL RECAUDADO

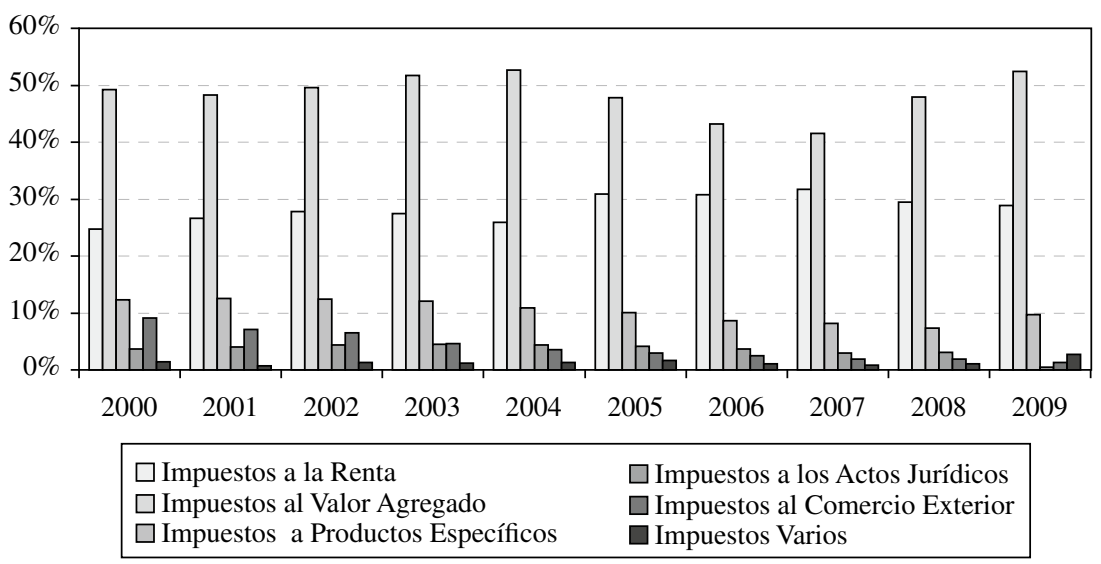

Fuente: Elaboración propia en base a información de Subdirección de Estudios del SII.

para el Impuesto Adicional de dueños extranjeros, según corresponda, cuando pagan el Impuesto Global Complementario. No obstante lo anterior, hay sectores económicos como por ejemplo contribuyentes de bienes raíces agrícolas, pequeños mineros artesanales y actividad de transporte terrestre que pueden tributar en base a renta presunta si cumplen con ciertos requisitos, también existen regímenes especiales para que empresas, cuyos ingresos por ventas no hayan excedido un promedio anual de 3.000 unidades tributarias mensuales en los tres últimos ejercicios, tributen en base a utilidades retiradas. Las remesas de utilidades al exterior de rentas de fuente chilena están afectas al Impuesto Adicional con una tasa del 35\%, sin embargo, la mayoría de los inversionistas extranjeros optan por suscribir un contrato (DL 600) con un régimen especial de invariabilidad tributaria y una tasa de $42 \%$.

Los trabajadores dependientes pagan mensualmente el Impuesto de Segunda Categoría, el cual es retenido por el empleador, mientras a los trabajadores independientes se les retiene un $10 \%$ de los honorarios devengados. Los trabajadores con más de un empleador, las personas que reciben retornos al capital superiores a 20 UTM y los trabajadores independientes, deben consolidar sus ingresos anuales y pagar el Impuesto Global Complementario (IGC), usando como créditos el Impuesto de Primera Categoría, el Impuesto de Segunda Categoría y las retenciones por honorarios. El ahorro de las personas naturales en el sistema financiero, siempre que no sobrepase los límites establecidos en la ley, da origen

$5 \mathrm{Al}$ año 2008 un $67,3 \%$ de los capitales efectivamente ingresados a Chile hasta ese año se habían materializado a través del DL 600. 
a un crédito de $15 \%$ del ahorro neto del año, para ser utilizado contra el IGC, el ahorro neto negativo da origen a un débito. Hay exenciones tributarias importantes para algunas ganancias de capital habituales y no habituales, y para el ahorro previsional. Las cotizaciones previsionales para el sistema de pensiones y salud son deducibles de la renta, las cotizaciones adicionales voluntarias al fondo de pensiones son deducibles irrestrictamente de la renta tributable, mientras las aportaciones adicionales al seguro de salud tienen un límite de 4,2 Unidades de Fomento. El IGC y el Impuesto de Segunda Categoría tienen las mismas tasas y se aplican sobre una escala progresiva de ocho tramos, con tasas de $0 \%, 5 \%$, $10 \%, 15 \%, 25 \%, 32 \%, 37 \%$ y $40 \%$. La tasa marginal máxima de $40 \%$ se aplica a los ingresos que exceden las 150 UTM mensuales.

A pesar de la progresividad de las tasas del IGC la recaudación del impuesto a la renta rinde poco (en promedio un $28 \%$ del total). Engel et al. (1999) evalúan la recaudación por tipo de impuestos según decil de ingreso para determinar los impactos en la distribución del ingreso de reformas tributarias utilizando un enfoque de equilibrio parcial con la Encuesta de Caracterización Socioeconómica CASEN de 1996. Sus resultados señalan que la fracción de la carga tributaria total no varía mucho de un decil a otro, esto debido a que la estructura tributaria chilena combina un impuesto regresivo que recauda mucho (el IVA) con uno progresivo que recauda relativamente poco (el Impuesto a la Renta). La conclusión es que el impuesto a la renta recauda poco porque en Chile los ingresos son mayoritariamente bajos. Otra explicación para el bajo poder redistributivo del sistema tributario en Chile es la evasión. Barra y Jorrat (1999) determinan para el año 1997 que la tasa de evasión estimada en el IVA alcanzó un 19,7\%, la tasa de evasión para el Impuesto a la Renta de Primera Categoría un 41,7\%, mientras que la tasa de evasión estimada para el agregado de los impuestos personales a la renta (Global Complementario, Segunda Categoría e Impuesto Adicional) se situó en torno al 35,8\%.

\section{MODELACIÓN DE REFORMAS TRIBUTARIAS}

En esta sección se discuten los principales resultados, la literatura de política de imposición óptima con modelos de equilibrio general estilizados, para luego discutir reformas impositivas con modelos de equilibrio general computables aplicados.

\section{Políticas Tributarias Óptimas con Modelos Estilizados}

La teoría de la imposición óptima parte con el trabajo de Ramsey (1927), quien considera el problema de elección de una política impositiva óptima en una economía estática con un agente representativo, cuando el gobierno tiene como único instrumento fiscal impuestos distorsionadores. Diamond y Mirrlees (1971) muestran que cuando el gobierno dispone de impuestos que gravan los bienes de consumo y las rentas del trabajo, bajo rendimientos constantes a escala y preferencias homotéticas es óptimo no gravar bienes intermedios. Chamley (1986) con un modelo dinámico determinístico con horizonte infinito y crecimiento exógeno demuestra que el impuesto óptimo sobre las rentas de capital 
debe ser cero en estado estacionario. También Judd (1985) con un modelo de horizonte infinito con agentes heterogéneos (capitalistas y trabajadores) concluye que es robusto no gravar el capital incluso aunque el gobierno no le asigne peso a la utilidad de los agentes capitalistas; esto se debe a que los trabajadores están peor producto de los efectos acumulados de las distorsiones en las decisiones intertemporales, prefiriendo distorsiones estáticas sobre la oferta de trabajo. En modelos de crecimiento endógeno como Chari et al. (1994) y Jones et al. (1997), la imposición sobre el capital también es cero, aunque los impuestos sobre el trabajo y el consumo deberían ser aproximadamente constantes. Al distinguir entre capital físico y capital humano Judd (1999) determina que es óptimo un impuesto cero al capital físico en el largo plazo; este resultado se mantiene para el capital humano si éste no tiene valor para los agentes como consumo final, además el ingreso laboral debe cargarse con impuestos en el largo plazo. La recomendación de política es cargar con impuesto todos los ingresos laborales, pero subsidiando la formación de capital humano. Hubbard y Judd (1986), Aiyagari (1995) y Imrohoroglu (1998) han enfatizado que si las familias enfrentan restricciones para pedir prestado y/o están sujetos a riesgos idiosincráticos no asegurables en el ingreso, entonces los sistemas de impuestos óptimos en general incluyen impuestos positivos al ingreso provenientes del capital. Conesa et al. (2009), caracterizan el impuesto óptimo al capital y al trabajo en un modelo de generaciones traslapadas a gran escala en el cual existe heterogeneidad no asegurable y riesgo en los ingresos, lo que genera un deseo para la redistribución y seguridad social, así encuentran que es óptimo en el largo plazo un sistema que carga impuestos fuertes al capital e impuestos al ingreso laboral de acuerdo a un impuesto plano (flat tax) con deducción.

\section{Políticas Tributarias con Modelos de Equilibrio General Computable Aplicados}

La aplicación de modelos de equilibrio general computable para analizar impuestos parte con Shoven y Whalley $(1972,1973)$; desde esa fecha los modelos simples han dado paso a modelos más grandes y complejos que capturan efectos indirectos que son difíciles de detectar, así la simulación de políticas en el campo de las finanzas públicas ha avanzado de manera exponencial.

La modelación de CGE aplicados para evaluar cambios tributarios ha sido utilizada en diversos países desarrollados y en desarrollo. Uno de los trabajos más importantes corresponde a Jorgenson y Wilcoxen (1997), quienes utilizando un modelo dinámico, multisectorial y multifamilia determinan que existen ganancias en el bienestar de unificar el impuesto a las empresas y personas, y al reemplazar el impuesto al capital por uno al consumo. Aunque estos resultados pudieron ser obtenidos mediante un modelo estilizado, a través de su modelación pudieron cuantificar desagregadamente las ganancias de tal cambio impositivo; Mun-Heng y Quian (2005) evalúan la reforma impositiva de 1994 en China, detectando a través de simulaciones que se obtuvieron ganancias en el bienestar pequeñas y sugiriendo extender el IVA a otros sectores actualmente no incluidos en la reforma; Gooroochurn y Milner (2005) usan un modelo CGE para examinar el impacto de cargar impuestos al turismo en la economía de Mauricio; Field (2007) analiza los efectos de la política industrial en Tailandia bajo diferentes opciones de impuestos; Radulescu y Stimmelmayr (2010) desarrollan un modelo 
CGE dinámico para analizar los impactos de la reforma al impuesto corporativo de 2008 en Alemania. En Chile existen algunas aplicaciones que han abordado el cambio de impuestos con CGE, pero no desde la perspectiva de una reforma tributaria, sino más bien para evaluar impactos económicos y ambientales de un aumento en el impuesto a los combustibles como en O'Ryan et al. (2003 y 2005), y la política comercial como en Harrison et al. (2002).

En años recientes, se ha avanzado desde el análisis de variables agregadas de las reformas tributarias con CGE hacia la obtención de resultados desagregados a nivel de hogares mediante la incorporación de la técnica de microsimulaciones, lo cual ha permitido generar análisis distributivos y de pobreza. Cororaton y Cockburn (2007) evalúan reformas comerciales compensadas con incremento al impuesto a la renta en un marco CGE con microsimulaciones determinando reducciones en la pobreza. Paulus y Peichl (2009) evalúan una reforma de un flat tax a las empresas y personas en Alemania con una combinación de CGE y microsimulaciones demostrando que existen claros beneficios de combinar ambas metodologías.

El atractivo especial de los modelos de equilibrio general computable aplicados, es que ellos son especialmente útiles para descubrir mecanismos no considerados por enfoques de equilibrio parcial. No obstante, Devarajan y Robinson (2005) señalan que la influencia de los CGE en las finanzas públicas ha sido significativa pero limitada, lo cual es explicado porque temas tan importantes como una reforma tributaria no pueden ser decididos con una sola clase de modelos, su influencia ha sido mayor cuando los resultados del modelo coinciden con resultados obtenidos desde otro tipo de análisis, incluyendo modelos estilizados, modelo de equilibrio parcial y modelos de microsimulaciones. Por estos motivos la aspiración de este trabajo es convertirse en una herramienta para encauzar el tema y entregar un soporte cuantitativo para los hacedores de políticas públicas.

TABLA 1

CARGA TRIBUTARIA DE CADA DECIL AL AÑO 2003 SEGÚN TIPO DE IMPUESTO*

\begin{tabular}{|rcccc|}
\hline Decil & $\begin{array}{c}\text { Tributación } \\
\text { Total }\end{array}$ & $\begin{array}{c}\text { Tributación } \\
\text { IVA }\end{array}$ & $\begin{array}{c}\text { Tributación } \\
\text { Renta }\end{array}$ & $\begin{array}{c}\text { Tributación } \\
\text { Otros }\end{array}$ \\
\hline 1 & $42,27 \%$ & $34,21 \%$ & $0,29 \%$ & $7,76 \%$ \\
2 & $27,19 \%$ & $22,00 \%$ & $0,18 \%$ & $5,01 \%$ \\
3 & $24,50 \%$ & $18,95 \%$ & $0,21 \%$ & $5,35 \%$ \\
4 & $22,07 \%$ & $17,14 \%$ & $0,09 \%$ & $4,85 \%$ \\
5 & $21,90 \%$ & $16,68 \%$ & $0,13 \%$ & $5,09 \%$ \\
6 & $21,00 \%$ & $15,73 \%$ & $0,24 \%$ & $5,03 \%$ \\
7 & $20,44 \%$ & $14,97 \%$ & $0,32 \%$ & $5,15 \%$ \\
8 & $20,37 \%$ & $14,05 \%$ & $0,72 \%$ & $5,61 \%$ \\
9 & $21,08 \%$ & $13,57 \%$ & $1,66 \%$ & $5,84 \%$ \\
10 & $21,26 \%$ & $8,17 \%$ & $8,55 \%$ & $4,55 \%$ \\
\hline
\end{tabular}

* La alta carga tributaria del primer decil, que supera el 40\%, se explica según Cantallops et al. (2007) porque para los más pobres, una parte de los impuestos vinculados al consumo, es financiada con subsidios monetarios, los que no forman parte del ingreso para la medición de la carga tributaria.

Fuente: Cantallops et al. (2007). 


\section{LA MATRIZ DE CONTABILIDAD SOCIAL}

Para la calibración del modelo CGE aplicado a la economía chilena se utiliza una Matriz de Contabilidad Social, más conocida por su nombre en inglés Social Account Matrix (SAM), elaborada a partir de la Matriz Insumo Producto 2003 (Cuentas Nacionales, 2007). Esta matriz recrea el flujo circular de la renta y cuenta con una desagregación de trece sectores productivos (agropecuario "agro", madera "mad", pesca "mar", petróleo "pet", cobre "cob", minería no cobre "min", industria manufacturera "man", electricidad-agua "elec", construcción “cons", comercio “com”, transporte-comunicaciones "tyc”, servicios "ose”, servicios públicos " gob”), tres tipos de trabajo (no calificado, semicalificado y calificado) y cinco hogares representativos (quintiles de ingreso). Un resumen de los datos sobre consumo intermedio y valor agregado por sector económico que fueron utilizados para elaborar la matriz de contabilidad social se presentan en las Tablas 2 y $3^{6}$.

\section{El modelo CGE aplicado}

La modelación mediante equilibrio general computable es un proceso de optimización altamente no lineal, cuyo equilibrio se caracteriza por un conjunto de precios relativos y niveles de producción en cada industria tal que la demanda iguale a la oferta para todos los productos. Las funciones de demanda surgen de un proceso de maximización de la utilidad por parte de las familias, mientras que la oferta de los productores viene de un proceso de maximización de beneficios.

Aun cuando los impuestos típicamente aparecen en estos modelos en forma ad valorem, los sistemas impositivos modernos (personas, empresas, ventas, valor agregado, royalties, etc.) son mucho más complejos por diversidad de tasas, exenciones, franquicias. Esta situación lleva a la necesidad de simular dentro del modelo cambios en impuestos de alguna manera equivalentes a una forma ad valorem (Bhattarai y Whalley, 1998).

En este trabajo se adapta a la economía chilena el modelo de equilibrio general MAMS (Maquette for MDG Simulations), desarrollado por el Banco Mundial (ver Löfgren, H. y Díaz-Bonilla, C. 2009). Específicamente se simulan reformas tributarias que modifican las tasas efectivas del impuesto al valor agregado y el impuesto a la renta.

El modelo dinámico recursivo MAMS está divido en dos módulos. El primer módulo "intra-período" define un modelo CGE estático muy similar al modelo CGE Estándar IFPRI (Löfgren, 2002), el cual está dividido a su vez en bloques de precios, producción y comercialización, instituciones (familias, gobierno, resto del mundo), inversión, sistemas de restricciones y variables macroeconómicas. El segundo módulo "entreperíodos", corresponde a un conjunto de ecuaciones que actualizan la población, productividad, stock de factores, activos y deudas por parte de las instituciones. Las ecuaciones de este módulo incluyen variables rezagadas, sin embargo, no aplican para el año inicial ya que asumen valores fijos. Como otros modelos CGE, el MAMS incluye tres balances macroeconómicos: para el gobierno, el resto del mundo y ahorro-inversión.

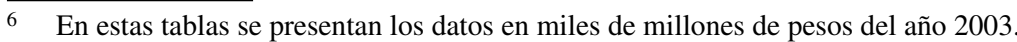



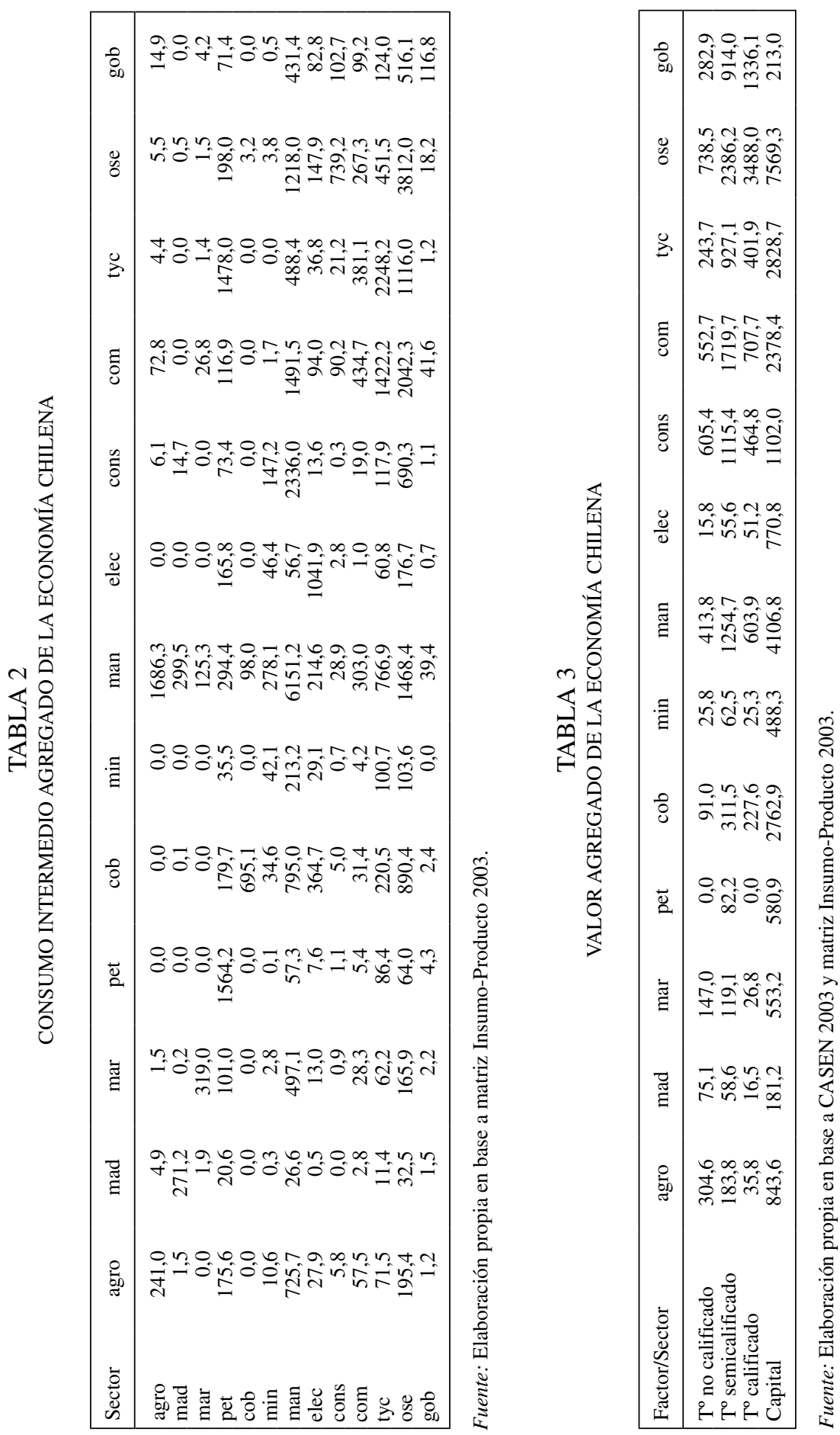


\section{Módulo Intra-Período}

En este módulo del modelo cada productor es representado por una actividad $a\left(Q A_{a}\right)$ que maximiza beneficios sujeto a la tecnología de producción CES (con elasticidad de sustitución $\sigma_{a}$ ) que mezcla inputs intermedios $\left(Q I N T A_{a}\right)$ y valor agregado $\left(Q V A_{a}\right)$. El valor agregado combina factores productivos tales como trabajo no calificado $\left(Q F_{\text {Lncal }}\right)$, semicalificado $\left(Q F_{\text {Lscal }}\right)$, calificado $\left(Q F_{\text {Lcal }}\right)$, y capital $\left(Q F_{K}\right)$, en una función CES (con elasticidad de sustitución $\sigma_{v a}$ ). La demanda de inputs intermedios de cada producto $c$ para la actividad $a$ proviene de una función Leontief que mezcla cada consumo intermedio $\left(Q I N T_{c, a}\right)$. Como parte de la decisión de maximización de beneficios, cada actividad utiliza un conjunto de factores productivos hasta el punto en donde el valor del producto marginal de cada factor es igual al precio del factor. En nuestra aplicación cada actividad produce un solo producto $\left(Q X_{c}\right)$, así los ingresos de la actividad están dados por la multiplicación del precio del producto y el nivel de producción.

Para los productos comercializados, la cadena empieza en la generación del producto doméstico desde las distintas actividades. Estos productos son sustitutos imperfectos (como resultado de diferencias en tiempos de entrega, calidad y distancia entre la locación de las distintas actividades). En una siguiente etapa, el producto doméstico agregado es asignado entre ventas domésticas $\left(Q D_{c}\right)$ y exportaciones $\left(Q X_{c}\right)$, expresadas por una función de transformación de elasticidad constante $\left(\sigma_{C E T}\right)$. En los mercados internacionales, las demandas por exportaciones nacionales son infinitamente elásticas dado los precios mundiales. Los precios recibidos por la producción exportada son expresados en moneda nacional con un tipo de cambio flexible, y ajustada por costos de transacción e impuestos a las exportaciones (si es que existen). El precio recibido por ventas domésticas es igual al precio pagado por los demandantes domésticos menos los costos de comercialización. La demanda doméstica es igual a la suma de demandas por consumo de las familias $\left(Q H_{c}\right)$, consumo del gobierno $\left(Q G_{c}\right)$, inversión $\left(Q I N V_{c}\right)$, inputs intermedios $\left(Q I N T_{c, a}\right)$, de comercialización y de transporte.

Las demandas de los mercados domésticos son realizadas sobre un producto compuesto de bienes domésticos e importaciones $\left(Q M_{c}\right)$, estas demandas son derivadas del supuesto que los agentes domésticos minimizan costos sujetos a sustitución imperfecta $\left(\sigma_{\text {Armington }}\right)$ dados los precios de los productos domésticos e importados; así las demandas por importaciones son satisfechas por las ofertas internacionales, que son infinitamente elásticas a los precios mundiales. Los precios pagados por los demandantes domésticos incluyen impuestos, aranceles y el costo de servicios de transacciones y transporte. Por último, cabe señalar que la flexibilidad de precios es lo que equilibra ofertas y demandas de los productos comercializados domésticamente.

Las familias (indexadas por $q$ de quintiles) reciben ingreso de los factores productivos directamente y reciben transferencias desde otras instituciones (el resto del mundo o el gobierno). Las familias usan su ingreso $\left(Y I_{q}\right)$ para pagar impuestos directos, gastar en consumo $\left(E H_{q}\right)$, hacer transferencias a otras instituciones y ahorrar (INSAV). Las familias consumen productos adquiridos a precios de mercado los que incluyen impuestos, costos de transporte y comercialización. El consumo de las familias es asignado entre los diferentes productos mediante las funciones de demanda provenientes del sistema de gasto lineal (LES) derivado de la maximización de una función de utilidad Stone-Geary. 
El gobierno recibe ingresos obtenidos mediante la aplicación de impuestos y transferencias del resto del mundo. El gobierno usa sus ingresos para adquirir productos para su consumo, pagar préstamos y realizar transferencias a las familias. El resto del mundo realiza pago de factores, transferencias de fondos hacia y desde instituciones domésticas, y préstamos, todos fijados en moneda extranjera. El ahorro extranjero, es decir, el déficit en cuenta corriente, es la diferencia entre los gastos e ingresos en moneda extranjera. El ahorro generado por el gobierno, familias y resto del mundo se utiliza como capital para realizar inversión.

\section{Módulo Entre-Períodos}

El módulo "entre-períodos" actualiza la población para cada año según una tasa de crecimiento de la fuerza laboral, también existe un ajuste en el stock de capital mantenido por las familias según el crecimiento de la población. El stock de capital total de la economía está conformado por capital del año anterior menos la depreciación, capital nuevo (inversión) y una tasa de ajuste exógena. La deuda extranjera está determinada por la deuda previa, nuevos préstamos, intereses, menos los pagos efectuados para la cancelación de deuda. El gobierno también emite deuda mediante bonos que son adquiridos por las familias y el resto del mundo. Finalmente, se realiza una actualización anual de la productividad de cada actividad económica en función de tendencias temporales.

\section{Reglas de Cierre Macroeconómicas del Modelo}

Este tipo de modelo puede incluir varios tipos de reglas de cierre macroeconómicas para el Gobierno, Sector Externo, y Ahorro-Inversión. Para esta aplicación se deja flexible el ahorro del gobierno a $\mathrm{PIB}^{7}$, se asume un tipo de cambio flexible e inversión determinada por el ahorro. La ilustración simplificada del funcionamiento intra-período del modelo se muestra en la Figura 2, y el funcionamiento dinámico del modelo MAMS puede resumirse gráficamente en la Figura 3.

\section{Mecanismo de Ajuste y Ecuaciones Seleccionadas del Modelo}

Por restricciones de espacio sólo se detallarán algunas ecuaciones del modelo, específicamente aquellas en las cuales aparecen las tasas de impuestos sujetas de simulación. En el caso de la modelación el impuesto al valor agregado se incorpora en la ecuación 1. El mecanismo de ajuste actúa ante una reducción en la tasa efectiva del IVA de la actividad $a\left(t v a_{a}\right)$ disminuyendo el precio del valor agregado $\left(P V A_{a}\right)$, lo cual cambia los precios relativos entre el valor agregado y el bien compuesto de bienes intermedios, ambos utilizados para generar la producción; el cambio en los precios relativos hace que se eleve la cantidad contratada de valor agregado $\left(Q V A_{a}\right)$ y disminuya la cantidad contratada del bien compuesto de bienes intermedios $\left(\right.$ QINTA $\left._{a}\right)$, por lo cual cae también su precio

\footnotetext{
Se intentó en una de las calibraciones del modelo asegurar la regla de balance estructural de gobierno, sin embargo, dado los ahorros del año base, se generaban grandes distorsiones en el tipo de cambio real desechándose esta opción de regla de cierre.
} 
FIGURA 2

\section{ILUSTRACIÓN SIMPLIFICADA INTRA-PERÍODO DEL MODELO MAMS}

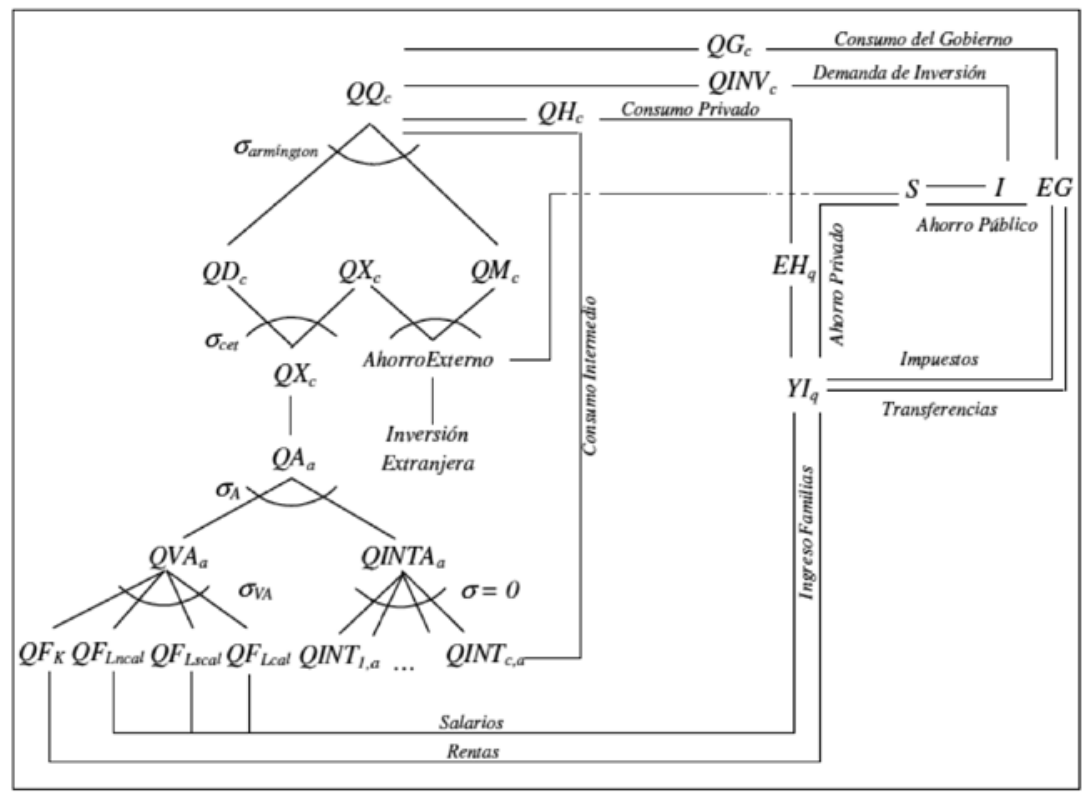

Fuente: Elaboración propia.

$\left(P I N T A_{a}\right)$. Ante el aumento en la contratación de valor agregado se incrementa la demanda por capital y trabajo (en sus distintos niveles de calificación), lo cual se traduce en un aumento en el pago a estos factores productivos. Lo anterior eleva los ingresos de los hogares incrementando la demanda por bienes y servicios (efecto ingreso), pero se eleva aún más en el sector que disminuyó su tasa efectiva de IVA por efecto sustitución. Volviendo al efecto sobre los precios, tenemos que una disminución en el bien compuesto de bienes intermedios y el precio del valor agregado se traduce en una disminución en el precio de la producción doméstica cuya producción es una función de ambos tipos de insumos. La caída en el precio de los bienes producidos domésticamente por la actividad $a$, se traduce finalmente en una disminución en el precio pagado por los consumidores por esos bienes domésticos, sustituyendo importaciones de ese bien ante el cambio en los precios relativos (aunque las importaciones de ese y los otros bienes también pueden incrementarse por el efecto ingreso). Adicionalmente a todos estos efectos intuitivos directos, se agrega el cambio en el resto de las variables endógenas del modelo, de tal modo de alcanzar el nuevo equilibrio ${ }^{8}$.

8 Esta forma de modelar los impactos de la variación en la tasa efectiva del IVA con el modelo CGE es compleja, menos directa e intuitiva de como se ha abordado en la literatura empírica la incidencia de impuestos a las ventas y al valor agregado. Por ejemplo, 
FIGURA 3

FUNCIONAMIENTO MODELO CGE DINÁMICO RECURSIVO

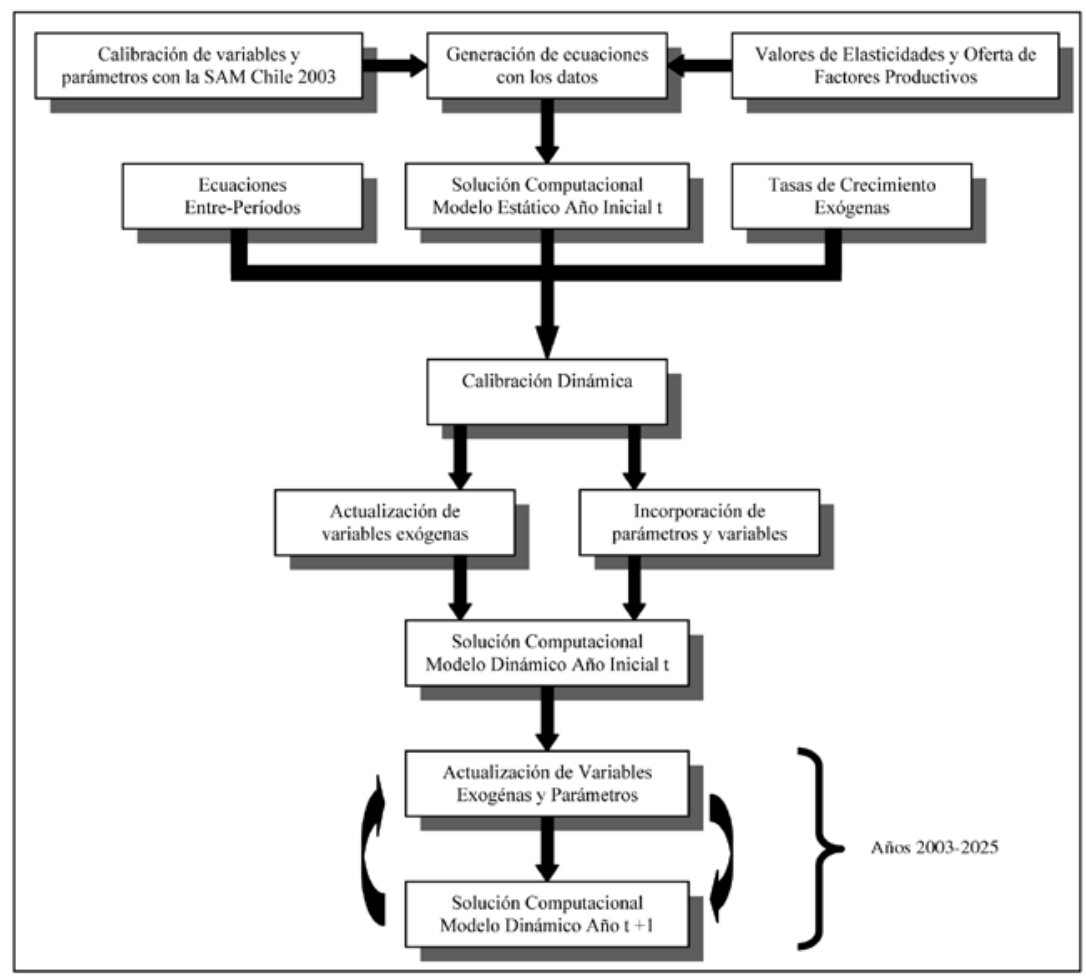

Fuente: Elaboración propia basada en Sánchez (2004).

(1)

$$
\begin{gathered}
W F_{f, t} \cdot \overline{W F D I S T}_{f, a, t}=P V A_{a, t} \cdot\left(1-t v a_{a, t}\right) \cdot Q V A_{a, t} \\
\cdot\left(\sum_{f^{\prime} \in F} \delta_{v a_{f^{\prime}, a}} \cdot\left(\operatorname{fprd}_{f^{\prime}, a, t} \cdot Q F_{f^{\prime}, a, t}\right)^{-\rho_{v a_{a}}}\right)^{-1} \cdot \delta_{v a_{f, a}} \cdot f p r d_{f, a, t}^{-\rho_{v a}} \cdot Q F_{f, a, t}^{-\rho_{v a_{a}}-1}
\end{gathered}
$$

En este modelo la incidencia del impuesto al ingreso no recae en la oferta laboral, sino en el ingreso final de los hogares, que incluye ingresos del trabajo, del capital y transferencias del gobierno. Así, un aumento en la tasa efectiva

Poterba (1996) y Besley y Rosen (1999) para bienes del sector retail en Estados Unidos muestran un traspaso cercano al $100 \%$ del aumento en el impuesto a las ventas sobre el precio final pagado por los consumidores finales. Mientras Jaramillo y Tovar (2009) para el caso de Colombia al analizar el IVA concuerdan con un traspaso cercano al 100\% al utilizar un bien agregado, aunque los resultados se vuelven bastante heterogéneos al utilizar categorías individuales de bienes. 
del impuesto a la renta afecta directamente al consumo y el ahorro, disminuye la demanda por productos, para luego afectar a todas las variables endógenas del modelo.

Específicamente las variaciones en la tasa efectiva de los impuestos directos cambian la ecuación que iguala el gasto de las familias $\left(E H_{h, t}\right)$ con el ingreso disponible neto de ahorro, y la ecuación que determina que el ahorro de las familias $\left(I N S S A V_{i, t}\right)$ es igual al ingreso de las familias $\left(Y I_{i, t}\right)$ menos impuestos directos $\left(T I N S_{i, t}\right)$ por la propensión marginal a ahorrar $\left(M P S_{i, t}\right)$.

$$
\begin{gathered}
E H_{h, t}=\left(1-\sum_{i \in I N S D N G} \operatorname{shii}_{i, h}\right) \cdot\left(1-\operatorname{MPS}_{h, t}\right) \cdot\left(1-\operatorname{TINS}_{h, t}\right) \cdot Y I_{h, t} \\
I N S S A V_{i, t}=\operatorname{MPS}_{i, t} \cdot\left(1-\operatorname{TINS}_{i, t}\right) \cdot Y I_{i, t}
\end{gathered}
$$

En ambos casos también se producen variaciones en la ecuación que definen el ingreso del gobierno $\left(Y G_{i, t}\right)$ como la recaudación generada por los impuestos directos $\operatorname{TINS}_{i, t}$ (a la renta), impuestos a actividades $t a_{a, t}$, impuesto al valor agregado $t v a_{a, t}$, aranceles $t m_{c, t}$, ingreso de los factores del gobierno y transferencia internacional en moneda doméstica. Esto además provoca variaciones en el resto de las variables endógenas del modelo.

$$
\begin{aligned}
Y G_{t} & =\sum_{i \in I N S D N G} \operatorname{TINS}_{i, t} \cdot Y I_{i, t}+\sum_{f \in F} t f_{f, t} \cdot Y F_{f, t}+\sum_{a \in A} t a_{a, t} \cdot P A_{a, t} \cdot Q_{a, t} \\
+ & \sum_{a \in A} t v a_{a, t} \cdot P V A_{a, t} \cdot Q V A_{a, t}+\sum_{c \in C M} t m_{c, t} \cdot p w m_{c, t} \cdot Q M_{c, t} \cdot E X R_{t} \\
& +\sum_{c \in C E} t e_{c, t} \cdot p w e_{c, t} \cdot Q E_{c, t} \cdot E X R_{t}+\sum_{c \in C} t q_{c, t} \cdot P Q_{c, t} \cdot Q Q_{c, t} \\
& +\sum_{f \in F} Y I F_{g o v, f, t}+\sum_{i \in I N S D N G} T R I I_{g o v, i, t}+t r n s f r_{g o v, r o w, t} \cdot E X R_{t}
\end{aligned}
$$

\section{Supuestos y Limitaciones de la Modelación}

Para la calibración del modelo se definen en el escenario base una serie de parámetros y tasas de crecimiento, que son calculados u obtenidos de la literatura. Los parámetros exógenos utilizados son la tasa de crecimiento para el PIB de $5,4 \%$ (basado en el crecimiento promedio de la economía entre 1987 y 2010); tasa de crecimiento exógena de la productividad total de factores de $0,05 \%$ (promedio entre 1960 y 2004 a partir de datos de Vergara (2005)); crecimiento de la fuerza laboral de 2,5\% (promedio entre 1987 y 2009); tasa de crecimien- 
to en el consumo del gobierno de 7,3\% en bienes y servicios, $5 \%$ en gasto de personal y 7,3\% de las transferencias (promedio entre 1999 y 2008 con datos de DIPRES); dada la variabilidad en la inversión extranjera directa la tasa de crecimiento anual de $9,5 \%$ se calcula a partir de la mediana entre 1996 y 2009; crecimiento en el endeudamiento privado en el extranjero de $8,5 \%$, endeudamiento público en el extranjero de $-12,6 \%$, endeudamiento privado interno de $3,4 \%$ y endeudamiento público interno de -29,8\% (promedio entre 1998 y 2010 con datos del Banco Central de Chile); finalmente, se utiliza la tasa de retorno del capital de 18,8\% (Benavente, De Gregorio y Nuñez, 2005). En general, las elasticidades utilizadas provienen de la literatura internacional, es así como se puede mencionar la elasticidad entre capital y trabajo de 0,9 obtenida de Claro (2003); la elasticidad entre valor agregado e input intermedio agregado de 0,8 ; la elasticidad del gasto en el sistema de demanda LES igual a uno y parámetro de Frisch igual a -2,4 (Nguessa, 2004); la elasticidad CET de la función de transformación entre producción doméstica y exportaciones, así como también la elasticidad Armington de producción doméstica e importaciones son extraídas de Jung y Thorbecke (2003) que utilizan elasticidades de 1,2 para sectores primarios, 0,8 industria y 0,6 servicios.

Finalmente, para sensibilizar los resultados se consideran diversos valores de parámetros y elasticidades que pudiesen generar un impacto relevante. Específicamente, se utiliza una tasa de crecimiento del PIB más conservadora de $3,8 \%$ (promedio entre 2000 y 2010) y elasticidades menores entre capital y trabajo $(0,4)$; valor agregado e input intermedio agregado $(0,2)$; y elasticidad del gasto en el sistema de demanda LES $(0,2)$.

El modelo aplicado no considera explícitamente la existencia de una cuenta "Empresas" en la matriz de contabilidad social por dos razones. En consecuencia, la estrategia de modelación es fundir la cuenta "Empresa" con la cuenta "Familias" en la matriz, generando cinco familias representativas que posee factores capital y trabajo.

Cabe destacar que la principal limitación del modelo es asumir una oferta laboral exógena, así cualquier cambio en la demanda de trabajo se traduce sólo en variaciones de los salarios; esto contrasta con los estudios de Mizala et al. (1998) quienes encuentran una elasticidad de la oferta laboral masculina de 1,07 y femenina de 1,89; con Cowan et al. (2005) quienes afirman que los salarios en Chile son "rígidos"; y con Céspedes y Tokman (2005), que señalan una alta elasticidad de la oferta laboral secundaria al ciclo económico, al retirarse jóvenes y mujeres del mercado laboral para volver cuando las condiciones laborales se tornen más favorables. En consecuencia, el supuesto de oferta laboral exógena genera sesgos en nuestros resultados, ya que esperaríamos un ajuste vía cantidad más que a través de los salarios; adicionalmente se esperarían cambios en la participación y en la composición de la fuerza laboral por género. También existen muchos efectos económicos indirectos imposibles de considerar en este tipo de modelación, porque dependen de las variaciones en el trabajo dependiente e independiente, formal e informal, mayor utilización de incentivos al ahorro (cambio de ingresos laborales respecto a ingresos de capital), variaciones en las acciones de evasión tributaria, entre muchas otras. 
Otras limitaciones de la modelación son no considerar la existencia de desempleo, es decir, el mercado laboral se ajusta vía salarios, así los resultados generados para el mercado laboral deben ser considerados como tendencias de largo plazo; también al ser un modelo de equilibrio general dinámico recursivo y no uno de optimización intertemporal, la decisión de ahorro-consumo no se resuelve mediante un proceso de optimización microeconómica, sino más bien por una regla de cierre del modelo; y no dar cuenta de efectos en los impuestos directos sobre la inversión extranjera? .

Aún considerando todas estas limitaciones, este tipo de modelación tiene muchas ventajas, principalmente vinculadas a la desagregación intersectorial (en este caso 13 sectores económicos), de factores productivos (mano de obra no calificada, semicalificada, calificada y capital) y de familias en quintiles de ingreso, lo que permite obtener efectos de segundo orden, así como también conclusiones más específicas y detalladas de los efectos generales sobre la economía chilena en el horizonte de simulación del modelo (año 2025).

\section{IMPACTOS DE LA REFORMA TRIBUTARIA}

\section{Escenario Base}

El modelo es calibrado para generar un escenario desde el año 2003 (base de la matriz de contabilidad social) hasta el año 2025, este es el llamado "Escenario Base". Las tasas de los impuestos en este escenario corresponden a las tasas efectivamente pagadas el año inicial. Específicamente podemos mencionar que la tasa de impuesto sobre el valor agregado es muy disímil a nivel sectorial (ver Tabla 4), a pesar de las pocas excepciones que existen en el IVA, esto se explica porque las exportaciones y algunos sectores están exentos, así como también por la evasión. Las tasas efectivas promedio de impuestos directos, aranceles, IVA, específicos y sobre actividades, calculadas en base a cuentas nacionales y matriz de contabilidad social se presentan en la Tabla 5. La suma de todas ellas arroja una tasa efectiva promedio de todos estos impuestos de $18,6 \%$ respecto al PIB.

A partir de las sendas del escenario base en el modelo dinámico recursivo, se realizan seis simulaciones de cambios en impuestos, generados a través de un shock en las tasas de impuestos ad valorem en todo el período considerado. Las seis simulaciones son las siguientes: SIMIVA10 (disminución del IVA en 10\%); SIMIVA20 (disminución del IVA en 20\%); SIMDIR20 (aumento del impuesto a la renta efectivo del quintil más rico en 20\%); SIMDIR40 (aumento del impuesto a la renta efectivo del quintil más rico en 40\%); SIMIVADIR1020 (simultáneamente disminución del IVA en $10 \%$ y aumento de impuestos a la renta al quintil más rico en 20\%); SIMIVADIR2040 (simultáneamente disminución del IVA en $20 \%$ y aumento de impuestos a la renta al quintil más rico en $40 \%$ ).

9 Agostini y Jalile (2009) demuestran empíricamente que la inversión extranjera en países latinoamericanos reacciona negativamente a incrementos impositivos. 

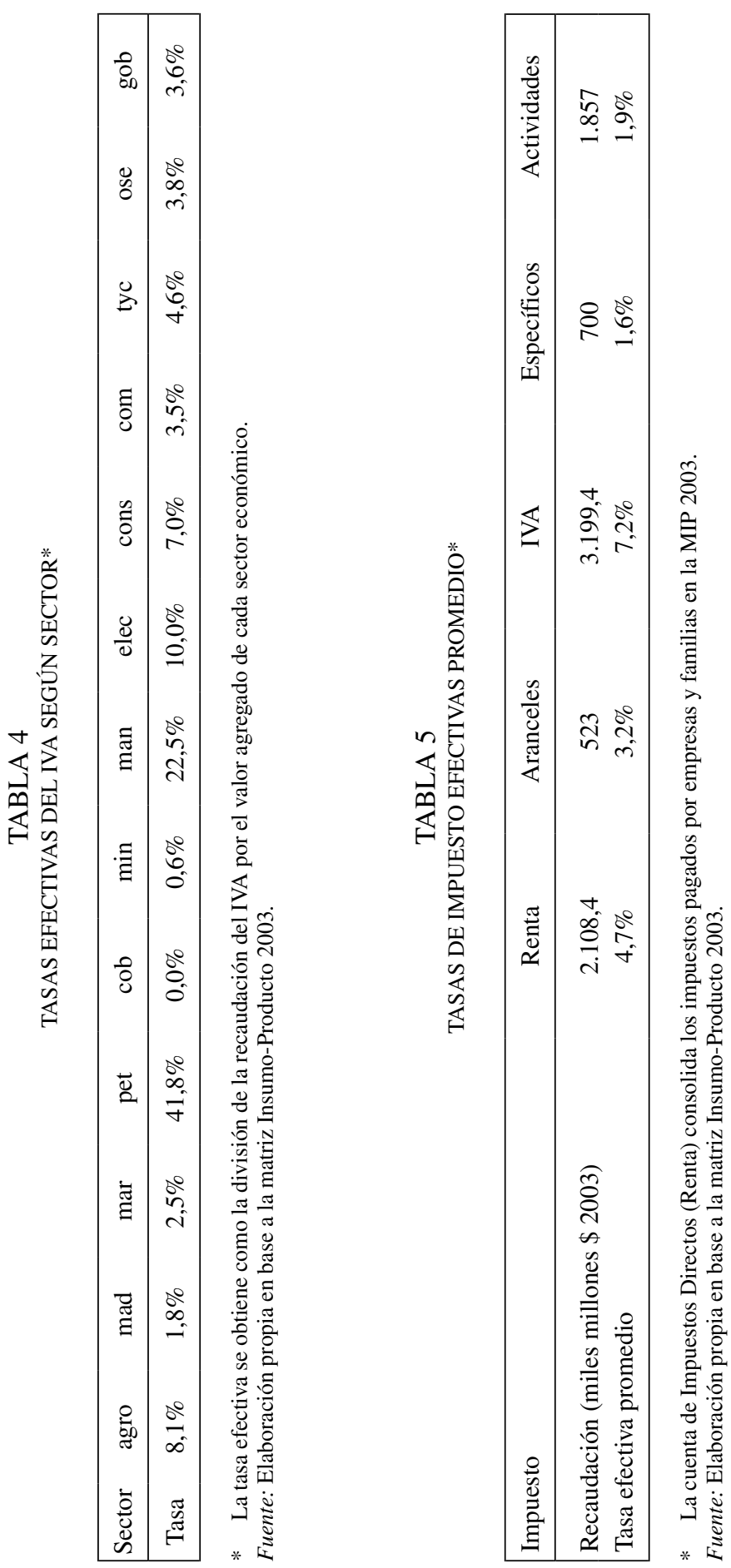


\section{Resultados de Simulaciones}

El escenario base y las seis simulaciones de reformas a la estructura impositiva son generados utilizando el modelo MAMS. Como en cualquier modelo CGE dinámico recursivo el escenario base y las simulaciones examinan los efectos directos e indirectos sobre la economía (desagregada en función de la matriz de contabilidad social utilizada).

Específicamente, el modelo dinámico recursivo genera una senda para las variables clave de la economía chilena durante el período 2003 a 2025, dada la calibración de parámetros exógenos (como la tasa de crecimiento del consumo del PIB, gobierno, transferencias, deuda, productividad, factores productivos, entre otros). La tasa de crecimiento promedio de la economía calibrada en todo el horizonte de evaluación es de un 5,4 en el escenario optimista y 3,8 en el escenario pesimista (estos valores varían ligeramente en el equilibrio del modelo para generar la optimización de la senda base y cada simulación).

Las simulaciones que bajan la tasa efectiva del IVA incrementan el ingreso disponible de las cinco familias representativas, por lo que parte de este mayor ingreso es gastada en bienes de consumo doméstico y otra se ahorra, aun cuando todos los quintiles aumentan el consumo es menor el aumento porcentual en el quintil 1. Las simulaciones que elevan el impuesto a la renta disminuyen el consumo de todos los quintiles, incluso los más pobres, aunque porcentualmente más el quintil 5 afectado directamente por el impuesto. Al contrario, las simulaciones que bajan el IVA y para compensar la recaudación incrementan la tasa efectiva del impuesto a la renta al quintil más rico, elevan el consumo de los quintiles 1 a 4 , y reducen el del quintil 5. Estos resultados son consistentes a escenarios con un crecimiento del PIB optimista y pesimista, así como también a elasticidades altas y bajas. En el caso del ahorro, se observa un aumento de éste en las simulaciones de reducción del IVA para los quintiles 4 y 5 (estos son los únicos que ahorran según la Encuesta de Presupuestos Familiares), aunque es porcentualmente mayor para el quintil 4. Las simulaciones que elevan el impuesto a la renta reducen el ahorro, aun cuando sorpresivamente la caída porcentual es mayor en el quintil 4 que en el quintil 5. Las simulaciones que bajan el IVA y elevan el impuesto a la renta elevan el ahorro del quintil 4, pero reducen el ahorro del quintil 5 (recordar que este quintil es el sujeto del aumento de impuesto a la renta). En las Tablas 6 y 7 se muestran la evolución del consumo y ahorro de las familias en las seis simulaciones respecto al escenario base.

El tipo de cambio real en el período de análisis (2003 a 2025) tiene una caída en todos los escenarios, lo que es resultado del crecimiento económico que eleva el poder adquisitivo de las familias, aumentando la demanda bienes domésticos que incrementan su precio relativo respecto a los precios internacionales, provocando la caída en el tipo de cambio real. Sin embargo, existe un impacto adicional sobre el nivel del tipo de cambio real debido a un efecto sustitución y un efecto ingreso, que explicamos en los siguientes tres párrafos.

Con la rebaja en el impuesto al valor agregado, se produce un efecto sustitución hacia los bienes afectos a este impuesto que ahora bajan su precio relativo respecto a aquellos bienes no afectos previamente, incrementando la demanda de los primeros en desmedro de la demanda de los segundos. El efecto ingreso se produce porque la rebaja en el IVA se traduce en un aumento en la demanda de valor agregado (trabajo y capital) por parte de las actividades productivas 


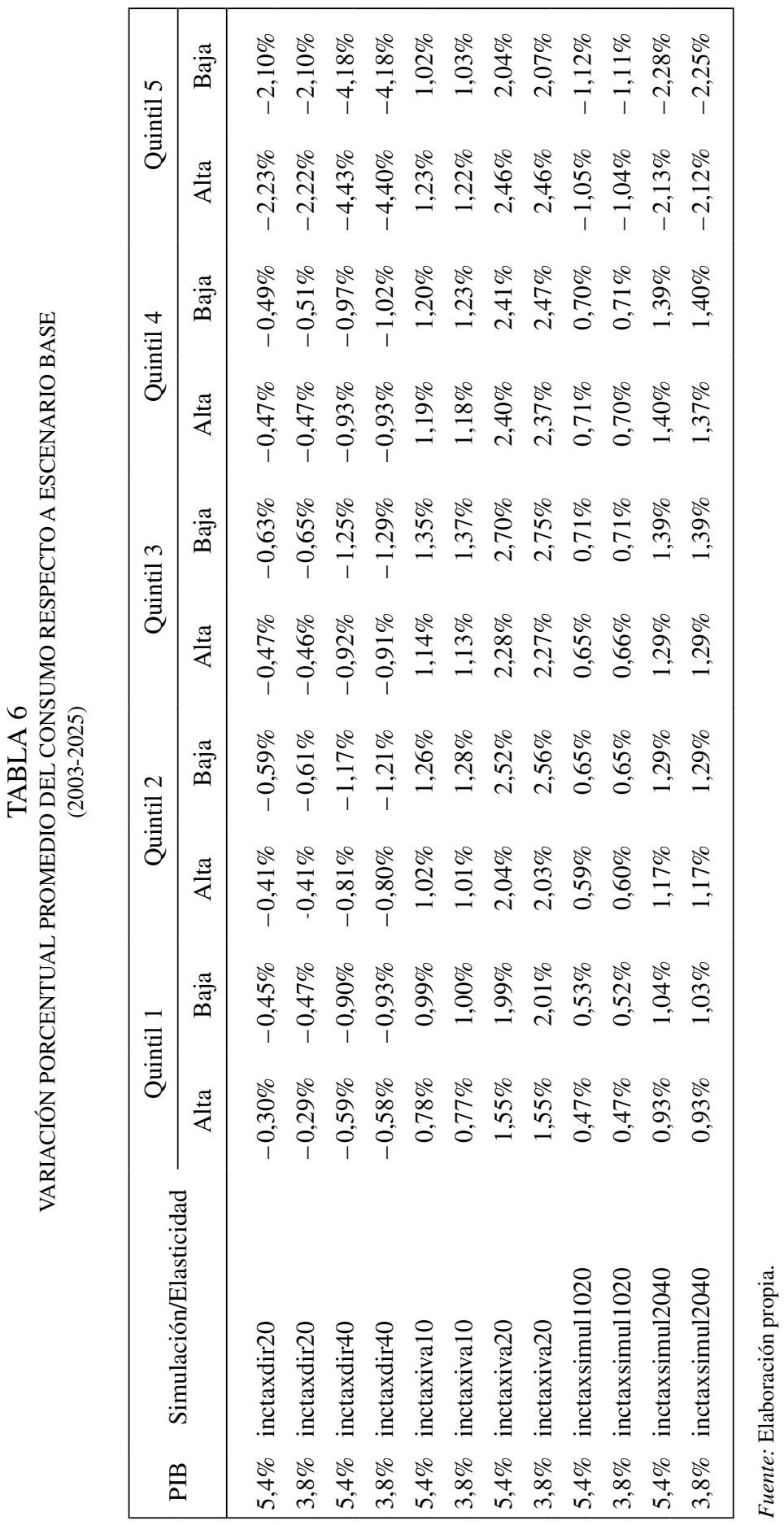


TABLA 7

VARIACIÓN PORCENTUAL DEL AHORRO DE LAS FAMILIAS

RESPECTO A ESCENARIO BASE

(2003-2025)

\begin{tabular}{|llrrrrr|}
\hline \multirow{2}{*}{ PIB } & \multirow{2}{*}{ Simulación/Elasticidad } & \multicolumn{2}{c}{ Quintil 4} & & \multicolumn{2}{c|}{ Quintil 5 } \\
\cline { 3 - 4 } \cline { 6 - 7 } & & Alta & Baja & & Alta & Baja \\
\hline $5,4 \%$ & inctaxdir20 & $-1,4 \%$ & $-1,4 \%$ & & $-1,3 \%$ & $-0,3 \%$ \\
$3,8 \%$ & inctaxdir20 & $-1,7 \%$ & $-1,7 \%$ & & $-1,3 \%$ & $-1,3 \%$ \\
$5,4 \%$ & inctaxdir40 & $-2,8 \%$ & $-2,8 \%$ & & $-2,6 \%$ & $-0,5 \%$ \\
$3,8 \%$ & inctaxdir40 & $-3,4 \%$ & $-3,5 \%$ & & $-2,6 \%$ & $-2,6 \%$ \\
$5,4 \%$ & inctaxiva10 & $1,9 \%$ & $2,0 \%$ & & $1,1 \%$ & $1,1 \%$ \\
$3,8 \%$ & inctaxiva10 & $2,1 \%$ & $2,3 \%$ & & $1,1 \%$ & $1,1 \%$ \\
$5,4 \%$ & inctaxiva20 & $3,8 \%$ & $4,1 \%$ & & $2,2 \%$ & $2,1 \%$ \\
$3,8 \%$ & inctaxiva20 & $4,3 \%$ & $4,6 \%$ & & $2,2 \%$ & $2,2 \%$ \\
$5,4 \%$ & inctaxsimul1020 & $0,5 \%$ & $0,6 \%$ & & $-0,3 \%$ & $-1,3 \%$ \\
$3,8 \%$ & inctaxsimul1020 & $0,4 \%$ & $0,5 \%$ & & $-0,2 \%$ & $-0,2 \%$ \\
$5,4 \%$ & inctaxsimul2040 & $1,0 \%$ & $1,2 \%$ & & $-0,6 \%$ & $-2,5 \%$ \\
$3,8 \%$ & inctaxsimul2040 & $0,7 \%$ & $0,9 \%$ & & $-0,5 \%$ & $-0,5 \%$ \\
\hline
\end{tabular}

Fuente: Elaboración propia.

con el consecuente aumento en el pago al factor trabajo, lo que eleva el ingreso disponible de las familias representativas y en consecuencia la demanda por bienes. La presión sobre el precio de los bienes genera una caída en el tipo de cambio real lo cual impacta a las exportaciones, importaciones y producción doméstica (cabe destacar que en el modelo aplicado en cada sector existe producción vendida domésticamente, exportaciones e importaciones según datos de cuentas nacionales, no existe un sector sólo exportador, sólo importador, o sólo no transable).

Las simulaciones que elevan el impuesto a la renta disminuyen el ingreso de las familias por lo que la demanda por bienes domésticos disminuye, lo cual hace caer el precio relativo de los bienes domésticos, elevando el tipo de cambio real.

En el caso de la rebaja en el IVA y la compensación mediante el aumento en el impuesto a la renta, el efecto ingreso es mayor al efecto sustitución, ya que los resultados muestran que el tipo de cambio real se deprecia (ver Tabla 8). El efecto ingreso reduce la demanda de bienes domésticos (por la reducción en el ingreso disponible) disminuyendo su precio, mientras que los precios de los bienes internacionales son exógenos para una economía pequeña. El efecto sustitución es provocado por la reducción del IVA que aprecia el tipo de cambio real, pero no alcanza a compensar el efecto ingreso, incrementándose levemente el tipo de cambio real por sobre el escenario base.

En el escenario base con una tasa del PIB de 5,4\% las exportaciones crecen en promedio un $2,6 \%$ y $2,4 \%$ al año (elasticidades altas y bajas), con una tasa del PIB de 3,8\% las exportaciones caen en promedio un $0,1 \%$ y $0,3 \%$ (elasticidades altas y bajas), todas partiendo en el año 2003 con un monto de 185.533 miles de millones de pesos. En las simulaciones SIMIVA se genera una caída de las exportaciones respecto al escenario base por la disminución en los precios 
TABLA 8

VARIACIÓN PORCENTUAL DEL TIPO DE CAMBIO REAL RESPECTO A ESCENARIO BASE

(2003-2025)

\begin{tabular}{|ccrr|}
\hline PIB & Simulación/Elasticidad & Alta & Baja \\
\hline $5,4 \%$ & inctaxdir20 & $0,67 \%$ & $0,69 \%$ \\
$3,8 \%$ & inctaxdir20 & $0,67 \%$ & $0,72 \%$ \\
$5,4 \%$ & inctaxdir40 & $1,33 \%$ & $1,40 \%$ \\
$3,8 \%$ & inctaxdir40 & $1,33 \%$ & $1,42 \%$ \\
$5,4 \%$ & inctaxiva10 & $-0,56 \%$ & $-0,64 \%$ \\
$3,8 \%$ & inctaxiva10 & $-0,59 \%$ & $-0,63 \%$ \\
$5,4 \%$ & inctaxiva20 & $-1,18 \%$ & $-1,32 \%$ \\
$3,8 \%$ & inctaxiva20 & $-1,18 \%$ & $-1,30 \%$ \\
$5,4 \%$ & inctaxsimul1020 & $0,13 \%$ & $0,08 \%$ \\
$3,8 \%$ & inctaxsimul1020 & $0,12 \%$ & $0,10 \%$ \\
$5,4 \%$ & inctaxsimul2040 & $0,26 \%$ & $0,18 \%$ \\
$3,8 \%$ & inctaxsimul2040 & $0,25 \%$ & $0,21 \%$ \\
\hline
\end{tabular}

Fuente: Elaboración propia.

relativos de éstas y en el tipo de cambio real; en las simulaciones SIMDIR las exportaciones se elevan por sobre el escenario base por los cambios en los precios relativos y el aumento en el tipo de cambio real, mientras en las simulaciones SIMIVADIR las exportaciones aumentan levemente sobre el escenario base por el incremento marginal del tipo de cambio real (ver Figura 5 y Tabla 8). Los sectores exportadores que caen con las reformas SIMIVA son la minería del cobre, resto de minería, pesca, madera, agrícola, servicios, manufacturero, comercio y transporte y comunicaciones, mientras el que sube es petróleo. Los sectores exportadores que elevan su volumen con las reformas SIMDIR son la minería del cobre, resto de minería, pesca, madera, agrícola, servicios, manufacturero, comercio, transporte y comunicaciones y petróleo. Los sectores exportadores que caen con las reformas SIMIVADIR son la minería del cobre, madera y servicios, mientras los sectores que crecen en volumen exportado son agrícola, resto de minería, pesca, comercio, petróleo, manufacturero, transporte y comunicaciones.

En el escenario base con una tasa del PIB de 5,4\% las importaciones crecen en promedio un 5,4\% al año (elasticidades altas y bajas), con una tasa del PIB de $3,8 \%$ las importaciones crecen en promedio un 3,9\% (elasticidades altas y bajas), todas partiendo en el año 2003 con un monto de 165.289 miles de millones de pesos. En las simulaciones SIMIVA se genera un aumento de las importaciones respecto al escenario base por el aumento en los ingresos de las familias y la caída en el tipo de cambio real; en las simulaciones SIMDIR las importaciones caen por sobre el escenario base por la disminución en el ingreso de las familias que se refuerza por el aumento en el tipo de cambio real; en las simulaciones SIMIVADIR las importaciones disminuyen levemente con respecto al escenario base por la caída marginal del tipo de cambio real (ver Figura 6 y Tabla 8) y efectos ingresos cruzados en los quintiles de ingreso. Los sectores importadores que caen con las reformas SIMIVA son petróleo y electricidad-gas-agua, mien- 
FIGURA 4

SUPERÁVIT FISCAL A PIB EN PERÍODO 2003 A 2025

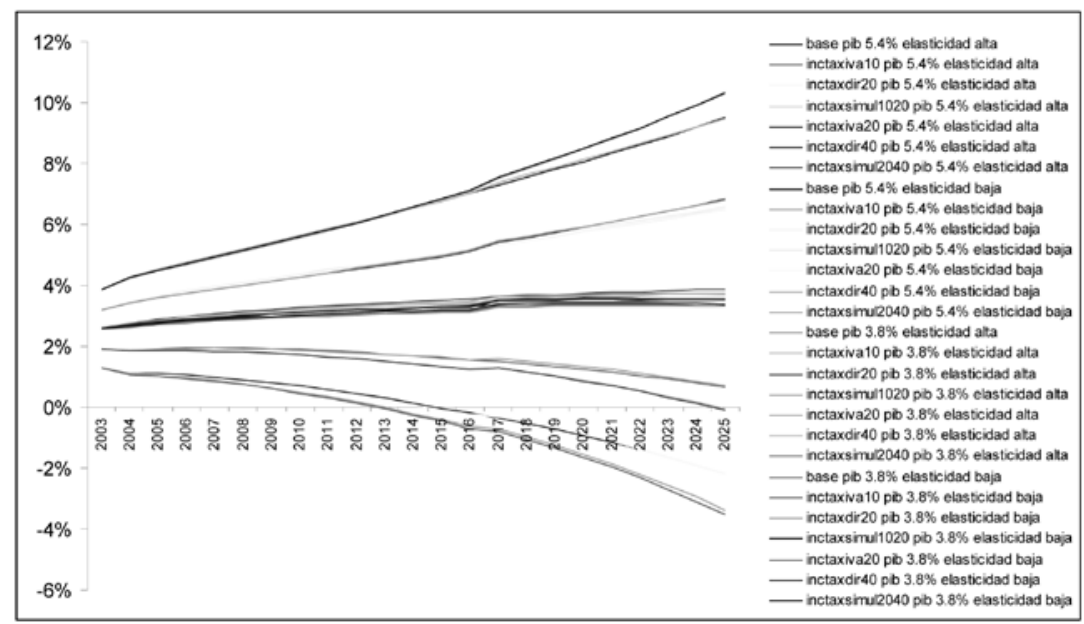

Fuente: Elaboración propia.

FIGURA 5

VARIACIÓN PORCENTUAL DE LAS EXPORTACIONES RESPECTO A ESCENARIO BASE

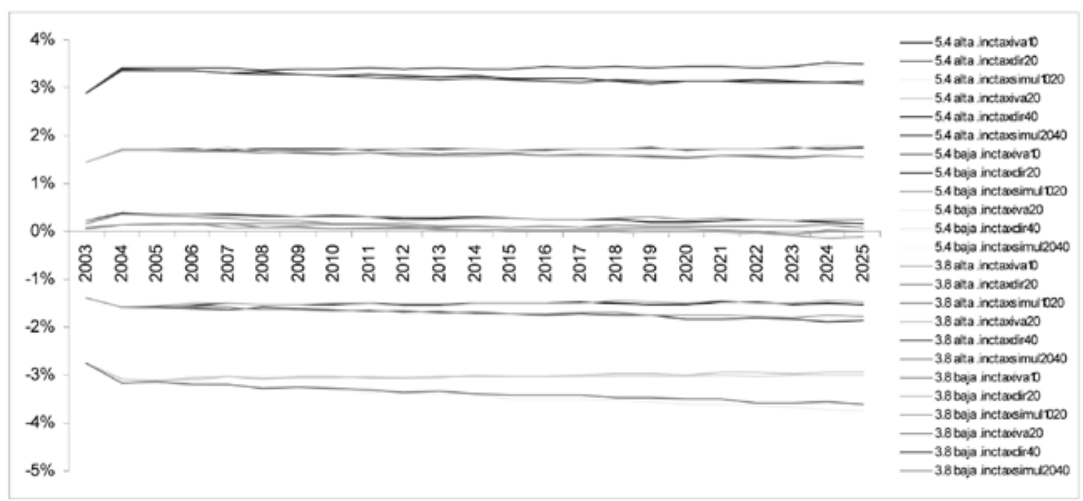

Fuente: Elaboración propia.

tras los que elevan el volumen importado son el agropecuario, madera, pesca, resto de minería, manufacturero, construcción, comercio, servicios, transporte y comunicaciones. Los sectores importadores que elevan su volumen con las reformas SIMDIR son la minería del cobre y electricidad-gas-agua, mientras los que disminuyen su volumen son el agropecuario, madera, pesca, petróleo, resto de minería, manufacturero, construcción, comercio, transporte y teleco- 
FIGURA 6

VARIACIÓN PORCENTUAL DE LAS IMPORTACIONES RESPECTO

A ESCENARIO BASE

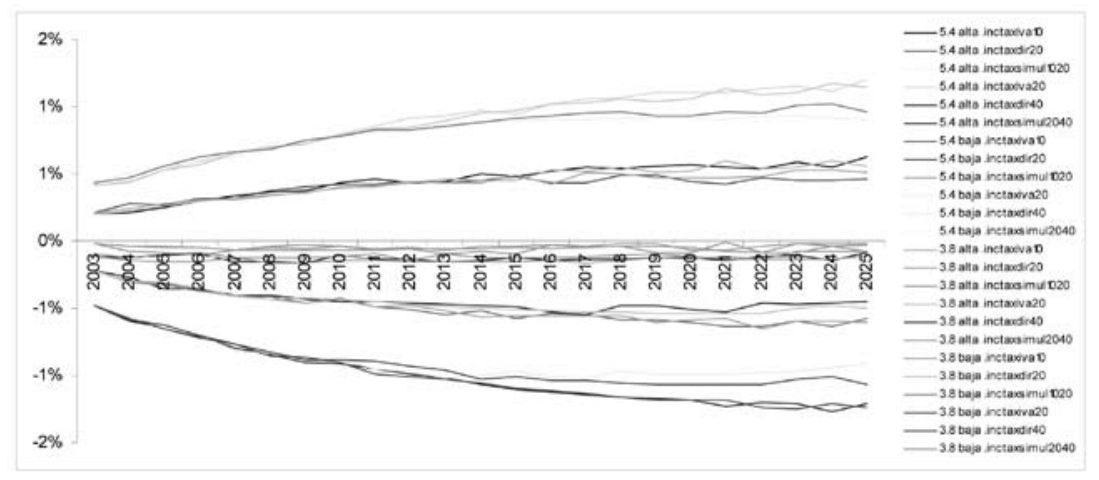

Fuente: Elaboración propia.

municaciones, y servicios. Los sectores importadores que caen con las reformas SIMIVADIR son petróleo y manufacturero, mientras los sectores que crecen en volumen importado son el agropecuario, madera, pesca, cobre, electricidad-gasagua, construcción, comercio, transporte y telecomunicaciones, y servicios.

Bajo el supuesto que el Gobierno mantiene su consumo, transferencias y deuda creciendo a las tasas históricas, más los resultados de la modelación económica, se obtienen las sendas de ahorro del gobierno (ver Tabla 9). Como es de esperar las reformas tributarias que elevan el impuesto a la renta del quintil más rico en $20 \%$ y $40 \%$ generan un aumento del superávit fiscal a PIB, específicamente en la simulación de un aumento del impuesto a la renta de $40 \%$ sube desde 3,82\% en el año base 2003 hasta 9,49\% (elasticidad alta y baja) al año 2025 con un crecimiento alto del PIB, mientras sube desde 3,82\% en el año base 2003 hasta $10,34 \%$ y $10,32 \%$ (elasticidad baja y alta) con un crecimiento bajo del PIB; en la simulación de un aumento del impuesto a la renta de $20 \%$ desde 3,21\% en el año base 2003 hasta 6,51\% y 6,56\% (elasticidad alta y baja) al año 2025 con un crecimiento alto del PIB, mientras $6,82 \%$ (elasticidad baja y alta) con un crecimiento bajo del PIB; en la simulación de una rebaja del IVA de $10 \%$ desde $1,92 \%$ en el año base 2003 hasta $0,68 \%$ y $0,72 \%$ (elasticidad alta y baja) al año 2025 con un crecimiento alto del PIB, mientras que se llega a generar justo el año 2025 un leve déficit a PIB de $-0,04 \%$ y $-0,11 \%$ (elasticidad baja y alta) con un crecimiento bajo del PIB; en la simulación de una rebaja del IVA de $20 \%$ desde $1,28 \%$ en el año base 2003 hasta $-2,17 \%$ y $-2,19 \%$ (elasticidad alta y baja) el año 2025 con un crecimiento alto del PIB, y un valor de $-3,37 \%$ y $-3,52 \%$ (elasticidad baja y alta) con un crecimiento bajo del PIB; en la simulación de una rebaja del IVA de $10 \%$ y aumento del impuesto a la renta de $20 \%$ el superávit fiscal a PIB va desde 2,57\% en el año base 2003 hasta 3,67\% y $3,66 \%$ (elasticidad alta y baja) al año 2025 con un crecimiento alto del PIB, mientras $3,49 \%$ y $3,40 \%$ (elasticidad baja y alta) con un crecimiento bajo del PIB; en la simulación de una rebaja del IVA de $20 \%$ y aumento del impuesto 
TABLA 9

VARIACIÓN PORCENTUAL DEL AHORRO DEL GOBIERNO

RESPECTO A ESCENARIO BASE

\begin{tabular}{|c|c|c|c|c|c|c|c|}
\hline \multirow{2}{*}{ PIB } & \multirow{2}{*}{ Simulación/Elasticidad } & \multicolumn{2}{|c|}{ Año 2003} & \multicolumn{2}{|c|}{ Año 2015} & \multicolumn{2}{|c|}{ Año 2025} \\
\hline & & Alta & Baja & Alta & Baja & Alta & Baja \\
\hline $5,4 \%$ & inctaxdir20 & $25,2 \%$ & $25,1 \%$ & $52,4 \%$ & $51,6 \%$ & $83,4 \%$ & $79,5 \%$ \\
\hline $3,8 \%$ & inctaxdir20 & $25,2 \%$ & $25,1 \%$ & $59,1 \%$ & $58,3 \%$ & $104,8 \%$ & $103,9 \%$ \\
\hline $5,4 \%$ & inctaxdir40 & $50,3 \%$ & $50,2 \%$ & $104,5 \%$ & $102,9 \%$ & $166,1 \%$ & $158,7 \%$ \\
\hline $3,8 \%$ & inctaxdir40 & $50,3 \%$ & $50,2 \%$ & $117,9 \%$ & $116,4 \%$ & $208,9 \%$ & $207,4 \%$ \\
\hline $5,4 \%$ & inctaxiva10 & $-25,0 \%$ & $-25,1 \%$ & $-50,3 \%$ & $-51,1 \%$ & $-80,8 \%$ & $-80,2 \%$ \\
\hline $3,8 \%$ & inctaxiva10 & $-25,0 \%$ & $-25,1 \%$ & $-56,8 \%$ & $-57,4 \%$ & $-101,1 \%$ & $-103,2 \%$ \\
\hline $5,4 \%$ & inctaxiva20 & $-49,9 \%$ & $-50,1 \%$ & $-100,7 \%$ & $-102,2 \%$ & $-161,8 \%$ & $-160,4 \%$ \\
\hline $3,8 \%$ & inctaxiva20 & $-49,9 \%$ & $-50,1 \%$ & $-113,6 \%$ & $-114,9 \%$ & $-202,4 \%$ & $-206,4 \%$ \\
\hline $5,4 \%$ & inctaxsimul1020 & $0,4 \%$ & $0,3 \%$ & $2,9 \%$ & $1,1 \%$ & $3,9 \%$ & $0,4 \%$ \\
\hline $3,8 \%$ & inctaxsimul1020 & $0,4 \%$ & $0,3 \%$ & $3,2 \%$ & $1,6 \%$ & $5,3 \%$ & $1,9 \%$ \\
\hline $5,4 \%$ & inctaxsimul2040 & $1,3 \%$ & $1,1 \%$ & $6,8 \%$ & $3,2 \%$ & $9,4 \%$ & $2,2 \%$ \\
\hline $3,8 \%$ & inctaxsimul2040 & $1,3 \%$ & $1,1 \%$ & $7,6 \%$ & $4,4 \%$ & $12,7 \%$ & $5,9 \%$ \\
\hline
\end{tabular}

Fuente: Elaboración propia.

a la renta de $40 \%$ el superávit fiscal a PIB va desde 2,59\% en el año base 2003 hasta $3,87 \%$ y $3,73 \%$ (elasticidad alta y baja) al año 2025 con un crecimiento alto del PIB, mientras 3,74\% y 3,53\% (elasticidad baja y alta) con un crecimiento bajo del PIB.

Es necesario destacar que la desagregación sectorial de un modelo de equilibrio general computable es especialmente útil para evaluar impactos indirectos difíciles de descubrir con otro tipo de metodologías. En orden a descubrir tales efectos, se presenta la Tabla 10 que contiene el nivel de actividad sectorial promedio para toda la senda modelada.

Las simulaciones que bajan los impuestos al valor agregado (SIMIVA10 y SIMIVA20) disminuyen el precio relativo de los bienes que tienen tasas efectivas altas e incrementan el ingreso disponible de las familias. Los resultados arrojan un aumento leve en la actividad de los sectores productivos agropecuario, madera, electricidad-gas-agua, construcción, comercio, transporte y comunicaciones, servicios y servicios públicos, mientras la actividad de los sectores petróleo y manufacturero aumentan relativamente más. Los sectores que disminuyen son principalmente exportadores como pesca, cobre y resto de minería al aumentar su precio relativo y no tener efecto ingreso significativo. Las simulaciones que suben los impuestos a la renta (SIMDIR20 y SIMDIR40), además de modificar los precios relativos disminuyen el ingreso disponible de las familias del quintil más rico (y también de los otros quintiles), y elevan el tipo de cambio real. Los resultados arrojan un aumento leve en la actividad de los sectores productivos exportadores como pesca y resto de minería, y un aumento mayor en el sector cobre. Los sectores que disminuyen su actividad son principalmente agropecuario, madera, petróleo, manufacturero, electricidad-gas-agua, comercio, transporte y telecomunicaciones, construcción, servicios y servicios públicos. Las simulaciones que elevan el impuesto a la renta y bajan el IVA (SIMIVADIR1020 y SIMIVADIR2040) reducen algo el efecto ingreso, de este modo los resultados reflejan principalmente el efecto sustitución de los cambios en los precios re- 


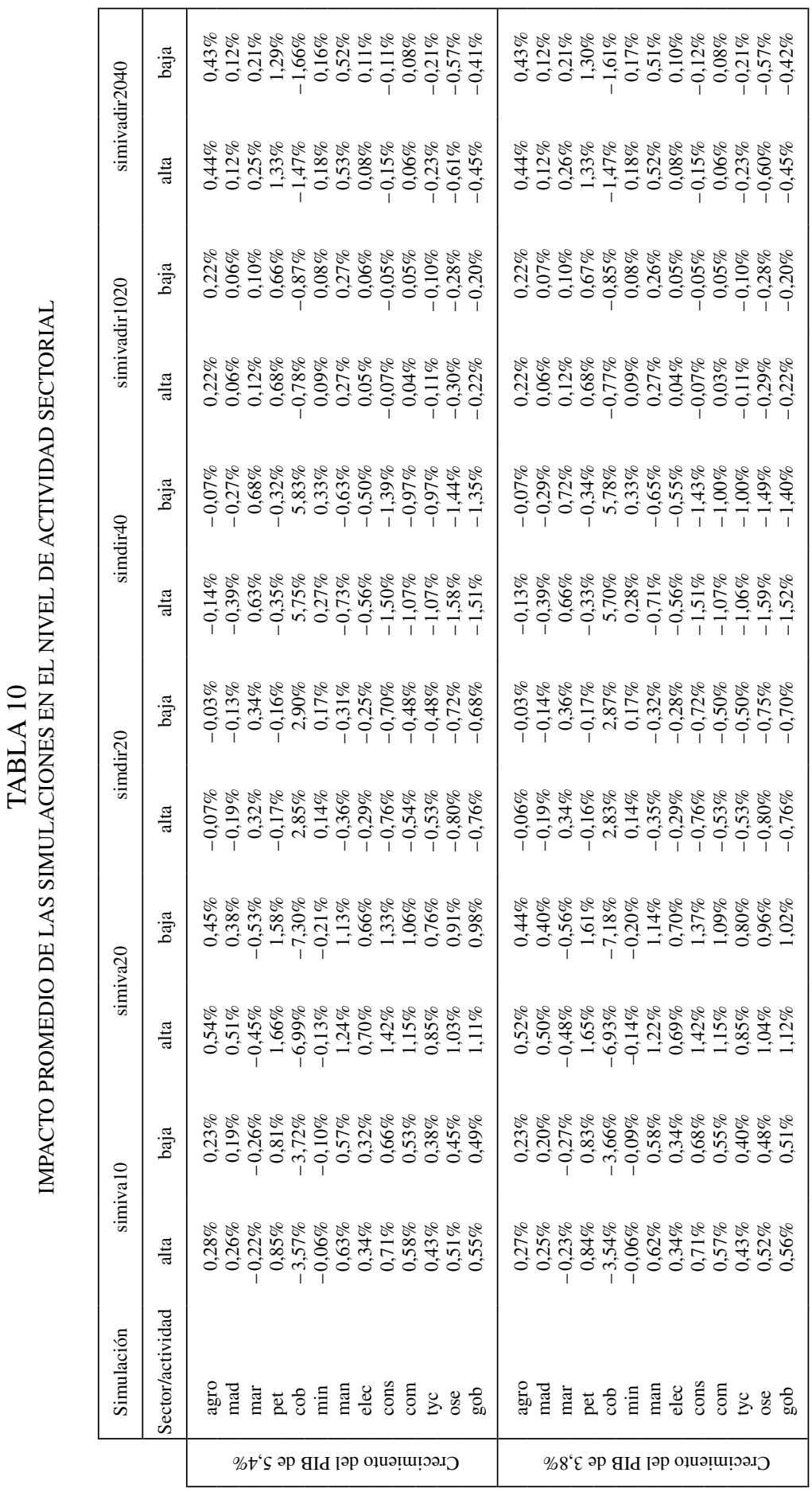


lativos. En efecto aumenta levemente la actividad de los sectores agropecuario, madera, pesca, petróleo, resto de minería, manufacturero, electricidad-gas-agua y comercio, a la vez disminuye la actividad de los sectores construcción, transporte y telecomunicaciones, servicios, servicios públicos, y en una mayor magnitud se reduce la actividad del sector cobre.

$\mathrm{El}$ impacto en los precios de mercado de los bienes y servicios finales se presenta en términos del crecimiento promedio anual durante toda la senda simulada 2003 y 2025 (ver Tabla 11). Los efectos en los precios varían dependiendo del supuesto de crecimiento en el PIB y elasticidades. Resultados consistentes con los distintos supuestos en los escenarios de rebaja en el IVA son una caída respecto a la evolución de la senda base en los precios de bienes y servicios asociados al sector petróleo, resto de minería, manufacturero y transporte y telecomunicaciones, mientras una subida respecto a la evolución de la senda base en los precios de bienes y servicios asociados al sector madera, construcción, comercio, servicios y servicios públicos. Resultados consistentes con los distintos supuestos en los escenarios de aumento en el impuesto a la renta del quintil más rico son una caída respecto a la evolución de la senda base en los precios de bienes y servicios asociados al sector agropecuario, madera, pesca, cobre, construcción, comercio y servicios públicos, mientras una subida respecto a la evolución de la senda base en los precios de bienes y servicios asociados al sector petróleo, manufacturero, electricidad-gas-agua, y transporte y telecomunicaciones. Finalmente, resultados consistentes con los distintos supuestos en los escenarios de rebajas en el IVA y aumento en el impuesto a la renta del quintil más rico son una caída respecto a la evolución de la senda base en los precios de bienes y servicios asociados al sector agropecuario, madera, pesca, cobre, resto de minería, electricidad-gas-agua, comercio y servicios, mientras una subida respecto a la evolución de la senda base en los precios de bienes y servicios asociados al sector petróleo y manufacturero.

Con respecto al mercado laboral que se asume segmentado y flexible, existe en el modelo una clasificación por tres niveles de calificación: mano de obra no calificada, semicalificada y calificada (ver Figuras 7, 8 y 9). Aquellos sectores que expanden su producción contratan más mano de obra y aquellos que se contraen la liberan, por lo que varían los salarios para equilibrar los mercados de cada uno de los niveles de calificación. El crecimiento promedio anual del salario del trabajo no calificado con un PIB alto varía entre 3,4\% y 4,6\% (elasticidad alta y baja), con un PIB bajo varía entre $1,7 \%$ y $2,6 \%$ (elasticidad alta y baja). El crecimiento promedio anual del salario del trabajo no calificado con un PIB alto varía entre 3,4\% y 4,6\% (elasticidad alta y baja), con un PIB bajo varía entre $1,6 \%$ y $2,5 \%$ (elasticidad alta y baja). El crecimiento promedio anual del salario del trabajo no calificado con un PIB alto varía entre 3,2\% y 4,4\% (elasticidad alta y baja), con un PIB bajo varía entre $1,6 \%$ y 2,4\% (elasticidad alta y baja).

Los resultados muestran que los escenarios SIMIVA elevan más los salarios promedio $^{10}$, en especial se incrementan porcentualmente más aquellos salarios con menor nivel de calificación (aunque en términos absolutos se incrementan más los con mayor nivel de calificación). Los escenarios SIMDIR bajan los

10 En el horizonte de evaluación desde los años 2003 a 2025. 


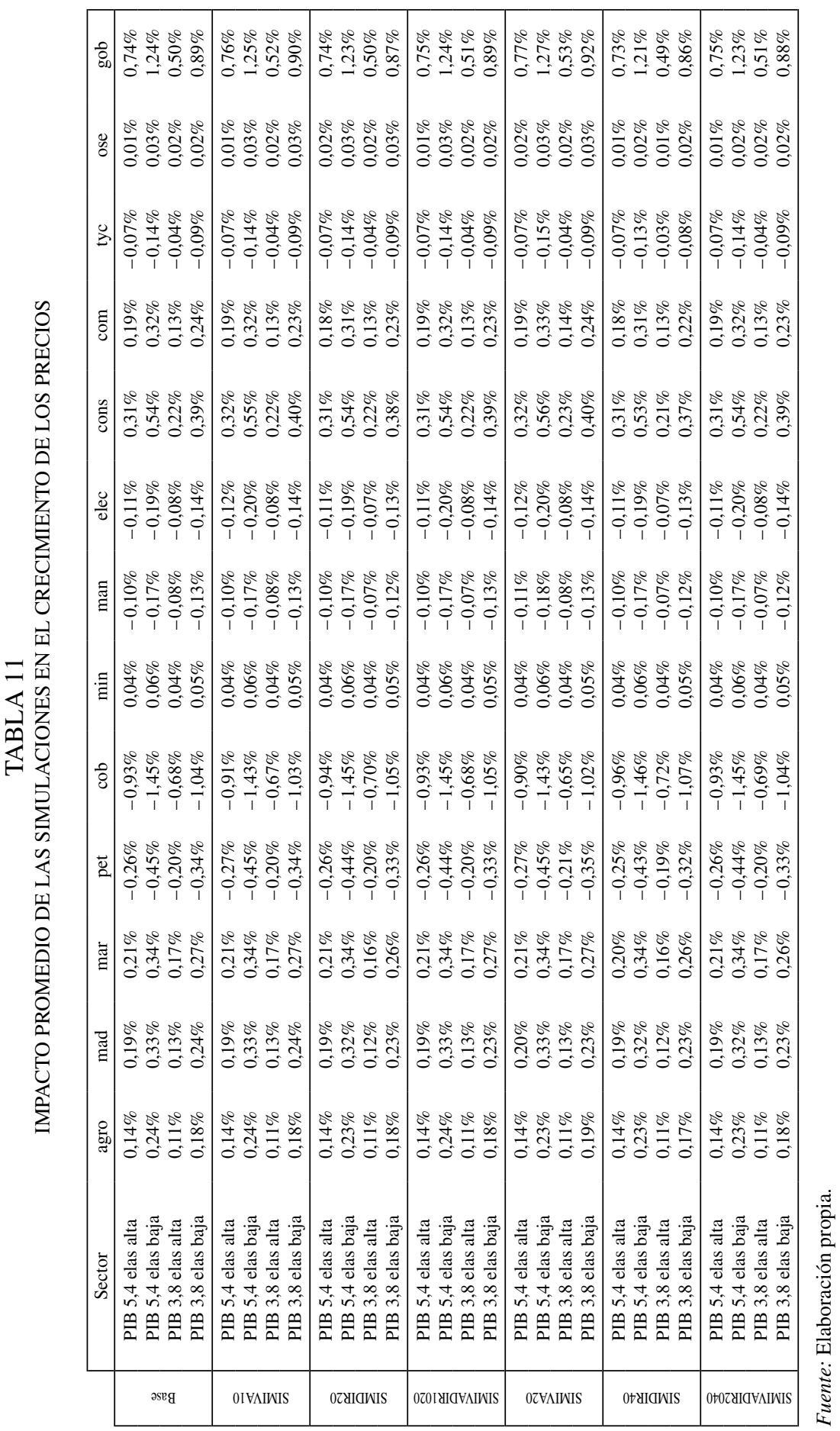


salarios en todos los niveles de calificación, aunque porcentualmente más los salarios de los trabajadores menos calificados. Los escenarios SIMIVADIR también incrementan los salarios respecto al escenario base pero de forma relativamente homogénea entre niveles de calificación, aunque en términos absolutos más que relativos crecen más los salarios con mayor calificación dado que parten de un nivel más alto. En términos temporales, podemos concluir que en el corto plazo elevan más los salarios las reformas que bajan el IVA en $20 \%$,

FIGURA 7

VARIACIÓN PORCENTUAL DEL SALARIO DE LA MANO DE OBRA NO CALIFICADA RESPECTO A ESCENARIO BASE

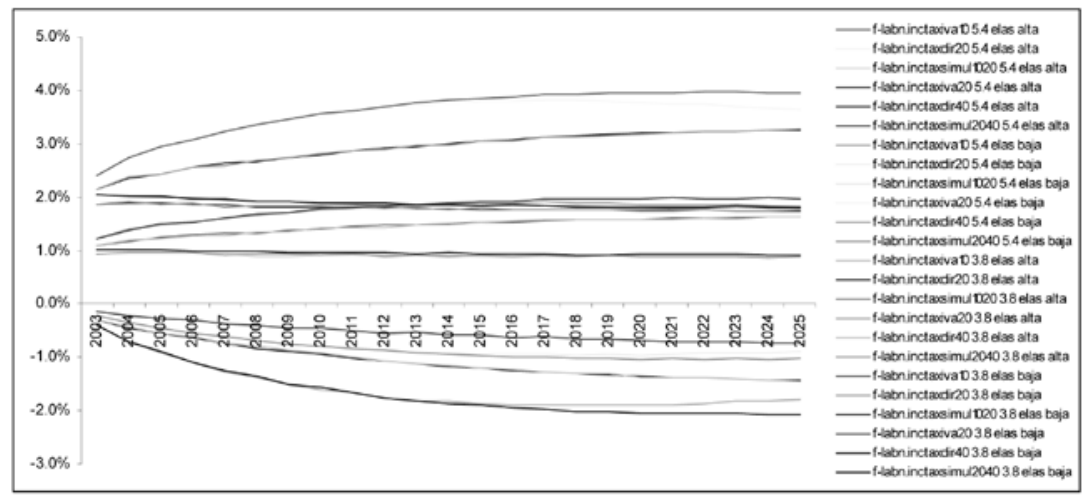

Fuente: Elaboración propia.

FIGURA 8

VARIACIÓN PORCENTUAL DEL SALARIO DE LA MANO DE OBRA SEMICALIFICADA RESPECTO A ESCENARIO BASE

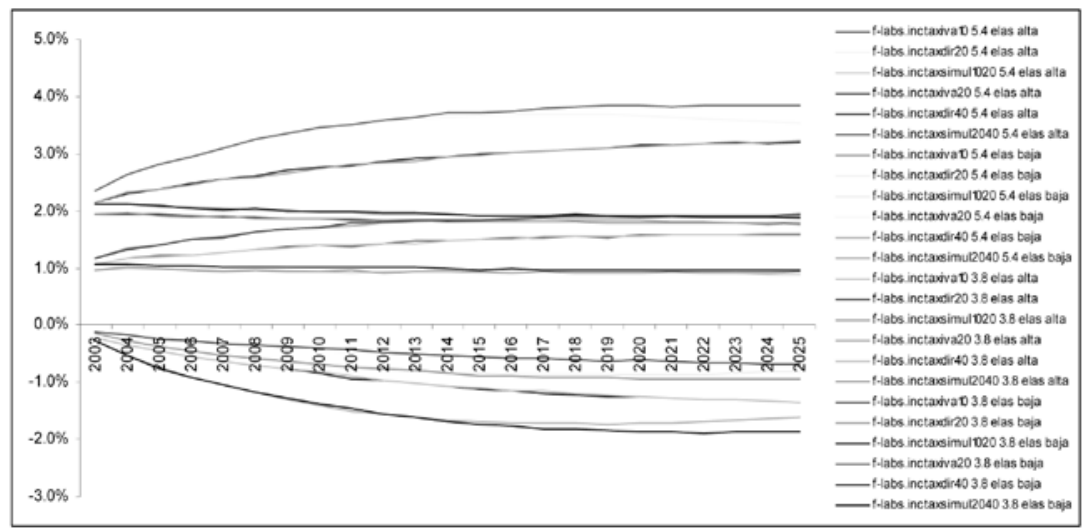

Fuente: Elaboración propia. 
FIGURA 9

VARIACIÓN PORCENTUAL DEL SALARIO DE LA MANO DE OBRA CALIFICADA RESPECTO A ESCENARIO BASE

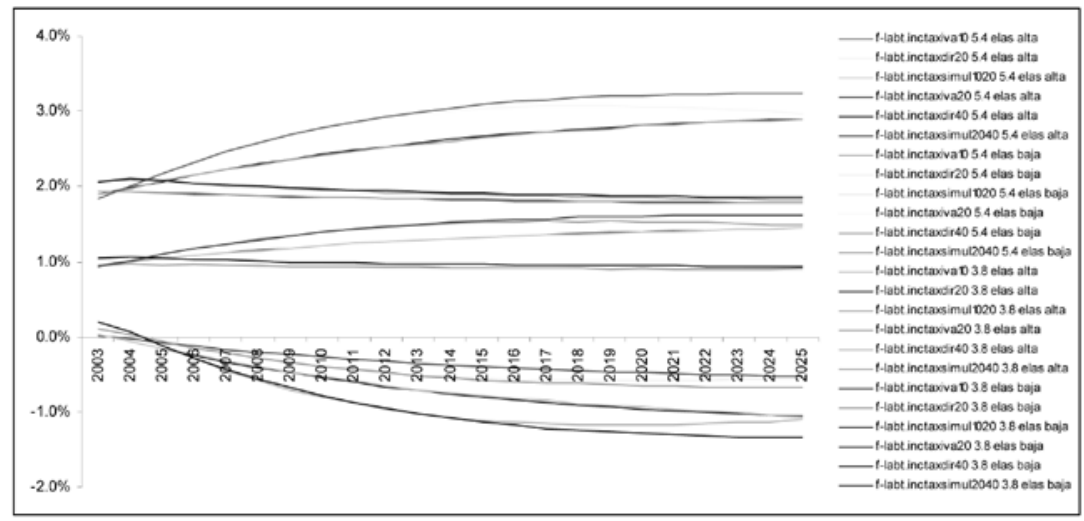

Fuente: Elaboración propia.

luego las simulaciones que bajan el IVA en $20 \%$ y aumentan el impuesto a la renta en $40 \%$ del quintil más rico, mientras que las simulaciones que elevan el impuesto a la renta en $40 \%$ del quintil más rico disminuyen los salarios de todos los niveles de calificación.

En base a los resultados anteriores más los efectos en la cantidad de trabajo contratado por nivel de calificación. El crecimiento promedio anual del ingreso bruto del quintil 1 con un PIB alto varía entre 6,1\% y 6,9\% (elasticidad alta y baja), con un PIB bajo varía entre $6,1 \%$ y $5,0 \%$ (elasticidad alta y baja). El crecimiento promedio anual del ingreso bruto del quintil 2 con un PIB alto varía entre $6,1 \%$ y $7,0 \%$ (elasticidad alta y baja), con un PIB bajo varía entre $6,1 \%$ y $5,1 \%$ (elasticidad alta y baja). El crecimiento promedio anual del ingreso bruto del quintil 3 con un PIB alto varía entre 6,0\% y 7,0\% (elasticidad alta y baja), con un PIB bajo varía entre $6,0 \%$ y $5,0 \%$ (elasticidad alta y baja). El crecimiento promedio anual del ingreso bruto del quintil 3 con un PIB alto varía entre $6,2 \%$ y $6,6 \%$ (elasticidad alta y baja), con un PIB bajo varía entre $6,2 \%$ y 4,8\% (elasticidad alta y baja). El crecimiento promedio anual del ingreso bruto del quintil 3 con un PIB alto varía entre 5,2\% y 4,9\% (elasticidad alta y baja), con un PIB bajo varía entre 5,2\% y 3,5\% (elasticidad alta y baja).

De las simulaciones tributarias analizadas se desprende que las reformas de baja en el IVA elevan los ingresos de las familias de todos los quintiles, aunque porcentualmente más los del quintil 4 y porcentualmente menos los del quintil 1. Las reformas que elevan el impuesto a la renta reducen los ingresos brutos de todos los quintiles, aunque porcentualmente menos los del quintil 1. Las reformas que bajan el IVA compensando con un aumento en el impuesto a la renta del quintil más rico elevan los ingresos brutos (antes de impuestos) de todos los quintiles en forma homogénea entre $0,5 \%$ y $1,5 \%$ respecto al incremento del escenario base (ver Figuras 10 a 14). Obviamente los ingresos netos de impuestos 
FIGURA 10

VARIACIÓN PORCENTUAL DEL INGRESO DEL QUINTIL 1 RESPECTO A ESCENARIO BASE

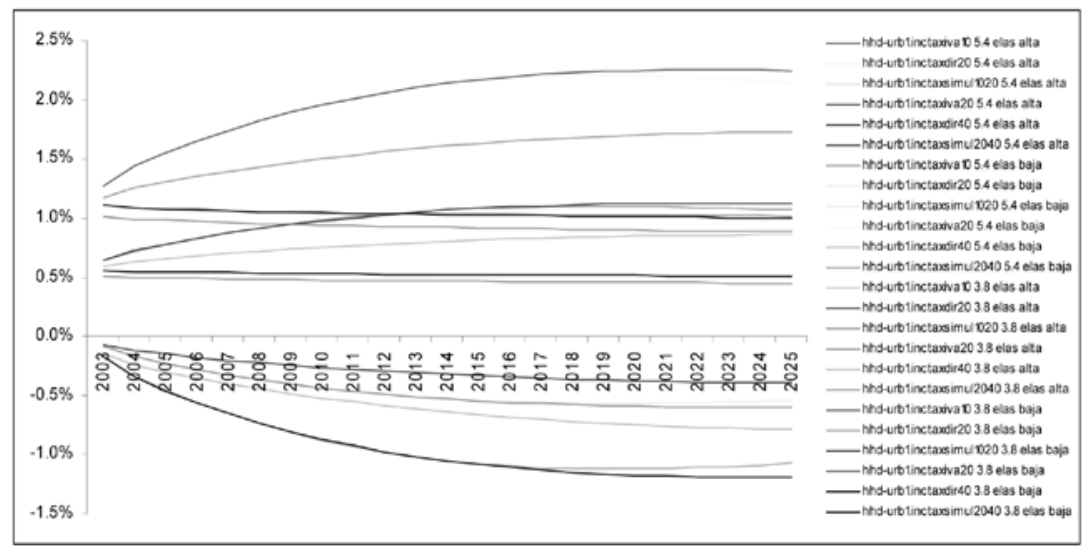

Fuente: Elaboración propia.

FIGURA 11

VARIACIÓN PORCENTUAL DEL INGRESO DEL QUINTIL 2 RESPECTO A ESCENARIO BASE

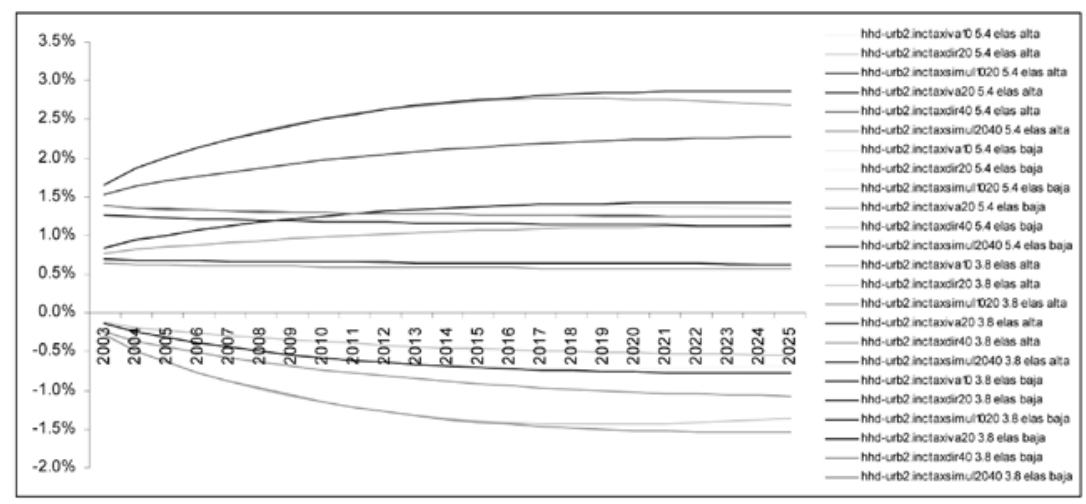

Fuente: Elaboración propia.

a la renta son reducidos en el caso del quintil 5 afecto al impuesto, lo que se observa al considerar la evolución en su nivel de consumo y ahorro.

Sin embargo, para realizar una desagregación y obtener alguna medida de los impactos en la distribución del ingreso que complementen los resultados anteriores, es necesario utilizar algún vínculo de los resultados de las variables del modelo CGE hacia microdatos. Esta metodología se denomina microsimulaciones (ver Bourguignon y Spadaro, 2006), ya que utiliza los cambios en 
FIGURA 12

VARIACIÓN PORCENTUAL DEL INGRESO DEL QUINTIL 3

RESPECTO A ESCENARIO BASE

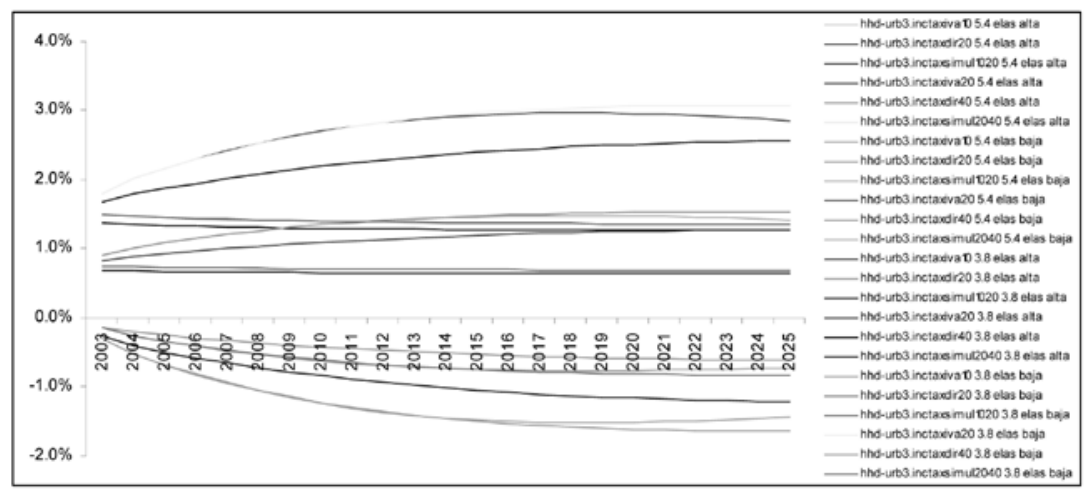

Fuente: Elaboración propia.

FIGURA 13

VARIACIÓN PORCENTUAL DEL INGRESO DEL QUINTIL 4

RESPECTO A ESCENARIO BASE

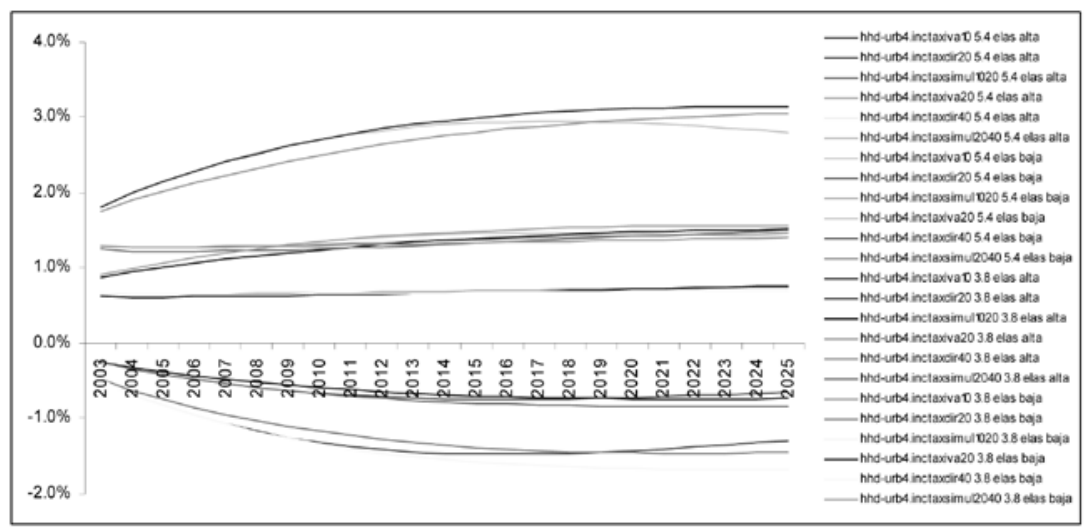

Fuente:Elaboración propia.

las variables del mercado laboral, tanto salario y cantidad demandada de cada factor productivo, obtenidas a partir de las simulaciones del modelo CGE y los combina con datos de encuesta a nivel de hogares.

El enfoque utilizado para estas microsimulaciones es llamado "top-down”, el cual usa un modelo CGE y un modelo de microsimulaciones en forma secuencial. Se comienza corriendo el modelo CGE y en un paso posterior los cambios en variables claves son traspasados al modelo de microsimulaciones. Este tipo de 
FIGURA 14

VARIACIÓN PORCENTUAL DEL INGRESO DEL QUINTIL 5 RESPECTO A ESCENARIO BASE

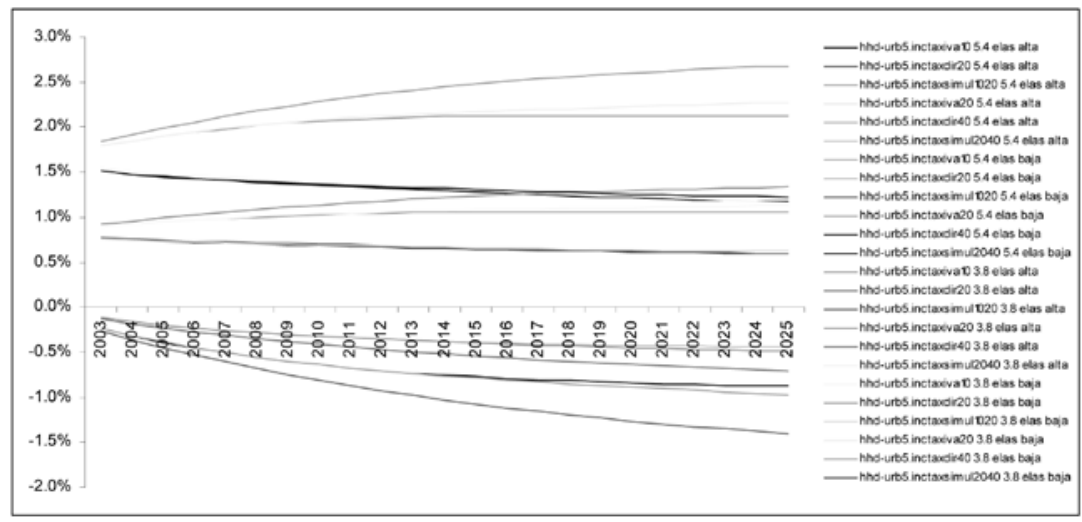

Fuente: Elaboración propia.

modelación tiene la ventaja de evitar el uso de supuestos de agente representativo $^{11}$, permitiendo considerar los efectos de equilibrio general, y además no requiere conciliación completa de datos micro y macro.

En este trabajo se realizaron microsimulaciones no paramétricas, metodología desarrollada por Ganuza et al. (2005). En esta modelación se asume que cambios ocupacionales pueden ser aproximados por un procedimiento de selección aleatoria dentro de una estructura segmentada del mercado del trabajo sobre una distribución derivada de datos de encuesta de hogares (para esta parte del análisis la Encuesta CASEN 2006) para así estimar simulaciones en el nivel de remuneraciones, y luego a partir de ellas, la distribución del ingreso y efectos en la pobreza.

El procedimiento estándar de la metodología de microsimulaciones no paramétricas considera los siguientes pasos: 1) El modelo CGE entrega el cambio en la cantidad de empleados de cada factor trabajo (no calificado, semicalificado y calificado) en cada uno de los sectores productivos incluidos en el modelo. 2) Se modifica el sector de empleo de cada ocupado en los microdatos de la encuesta CASEN 2006, de tal manera de replicar los cambios en el empleo sectorial que surgen del paso anterior. La elección de cada trabajador que cambia de sector es aleatoria. 3) Los ocupados en cada sector son agrupados en deciles de ingreso laboral según nivel de calificación, calculándose el ingreso promedio de cada decil, para que los trabajadores que cambian de empleo sean asignados aleatoriamente a alguno de los deciles de remuneraciones de su sector de empleo contrafactual. 4) Una vez realizada la simulación de cambio en la demanda laboral de los sectores productivos, se pasa al análisis del cambio en el ingreso laboral.

11 La cuenta "familias" en la matriz de contabilidad social y el modelo CGE. 
5) El modelo CGE entrega el cambio en el salario de cada nivel de calificación.

6) El ingreso laboral contrafactual se ajusta según el paso anterior.

En este análisis dado que los impuestos que pagan las familias se están modificando en las simulaciones, fue necesario agregar un paso adicional a esta metodología estándar de microsimulaciones, el cual se describe a continuación. Una vez generados los nuevos ingresos laborales para cada familia obtenidos de las microsimulaciones para cada escenario, se calculan con información complementaria el ingreso antes de impuestos, ingresos después de impuestos e ingresos después impuestos y transferencias. Para generar los ingresos antes de impuestos a los ingresos laborales se le suman los ingresos no laborales obtenidos de los datos de la encuesta CASEN 2006. Para calcular los ingresos después de impuestos, se resta a los ingresos antes de impuestos la carga tributaria del impuesto a la renta e IVA para cada decil de ingreso. Para generar el ingreso después de impuestos y transferencias, se suma al ingreso después de impuestos, las transferencias monetarias del gobierno para cada familia a partir de la información de la encuesta CASEN.

Cabe destacar que dada la falta de información, no es posible la aplicación de las reglas impositivas en detalle para cada persona (por ejemplo: se necesitaría saber si se tributa en sociedad conyugal, si generó crédito fiscal por ahorro en el sistema financiero, si se acogió a exenciones, entre otras). La estrategia para abordar el problema fue utilizar las tasas impositivas promedio por decil ${ }^{12}$ por el ingreso familiar descontados los subsidios monetarios (ver Tabla 1), lo cual puede ocultar algunos cambios en la distribución del ingreso y sesgar las estimaciones. Además, tampoco se toman en cuenta los cambios en la evasión lo cual genera otro sesgo que debe ser considerado al interpretar los resultados.

Con estas distintas definiciones de ingreso familiar se calculan varios índices de desigualdad (Coeficiente de Gini, razón Q5/Q1 y Percenti190/ Percentil10) para evaluar el impacto distributivo de las reformas tributarias propuestas. Los resultados sobre la distribución del ingreso de las familias para cada categoría de ingreso en el año base de la CASEN 2006 se muestran en la Tabla 12.

Si observamos los índices de Gini, P90/P10 y Q5/Q1 para el ingreso familiar antes de impuesto, ingreso familiar después de impuesto a la renta, ingreso familiar después de IVA e ingreso familiar después impuestos y transferencias, se aprecia un mejoramiento marginal en la distribución del ingreso en las diversas simulaciones, aunque la mayor equidad se logra al bajar el IVA y subir el impuesto a la renta al quintil más rico. Por lo anterior, se concluye que cambios en la estructura tributaria tienen espacio muy acotado para modificar la distribución del ingreso de las familias, aun cuando consideremos los efectos de equilibrio general en la economía.

Esto se explica porque aun cuando los escenarios que bajan el IVA elevan las remuneraciones de la mano de obra calificada en una menor proporción que la mano de obra con menor calificación, en términos absolutos los ingresos de los primeros aumentan más. Los escenarios que elevan el impuesto a la renta al quintil más rico disminuyen los ingresos de todos los quintiles, aunque pro-

12 Hay que destacar que en esta tabla la tributación del impuesto a la renta promedio para cada decil es positiva, aun cuando según el SII un $82 \%$ de la población no paga impuesto a la renta. 


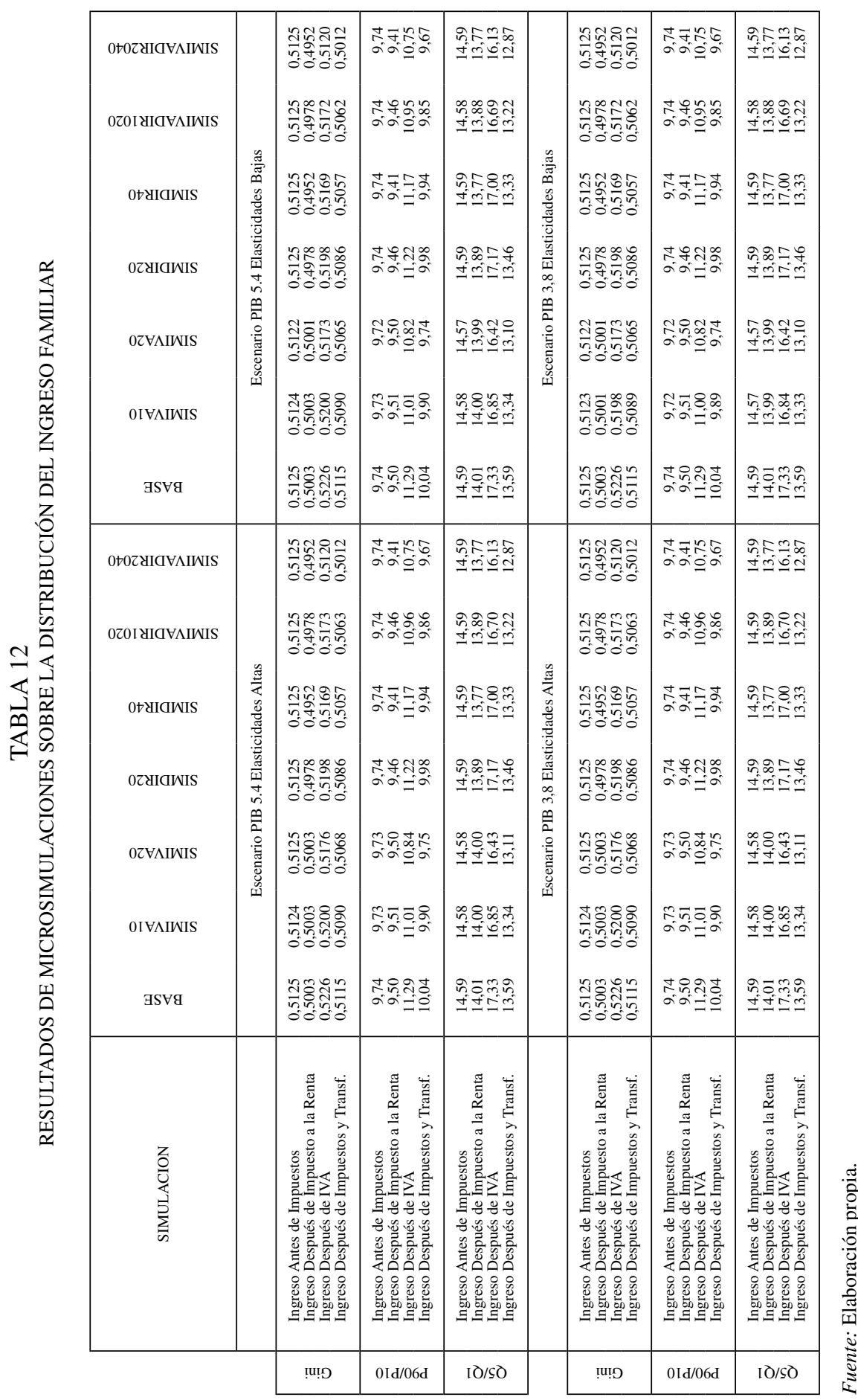


porcionalmente menos a los del quintil 1, de ahí la mejora en los indicadores de desigualdad. Mientras los escenarios que bajan el IVA y elevan el impuesto a la renta elevan las remuneraciones de forma homogénea y disminuyen los ingresos del quintil 5 vía aumento de impuestos a la renta.

Para evaluar los efectos de las reformas tributarias sobre la tasa de pobreza en el país, se traspasan las variaciones en las remuneraciones por nivel de calificación al ingreso del trabajo de cada individuo y además se ajusta la línea de pobreza definida por MIDEPLAN ${ }^{13}$. La línea de pobreza se basa en el costo de una canasta básica de subsistencia, por lo que ajustamos su valor en función de las variaciones en los precios del sector "agro" (alimentos) en el modelo CGE. Los resultados de la Tabla 13 señalan que la mejor opción para disminuir la tasa de pobreza es la rebaja del IVA, o alternativamente la rebaja del IVA y aumento del impuesto a la renta, mientras subir el impuesto a la renta eleva la pobreza. Lo anterior se explica porque las reformas de rebaja en el IVA bajan los precios de la canasta básica, pero a la vez elevan más las remuneraciones de la mano de obra no calificada, respecto a las simulaciones que bajan el IVA y elevan el impuesto a la renta.

Cabe destacar que los resultados anteriores asumen una oferta laboral exógena en el modelo, cambios en el impuesto a la renta no afectan la decisión ocio-trabajo, y además dado que el impacto de las simulaciones tributarias es traspasado completamente a los salarios, implica que no refleja las variaciones más significativas en la contratación de mano de obra. Por lo anterior, los resultados de estos efectos contrapuestos sesgan parcialmente los resultados en la distribución del ingreso y con mayor fuerza en la medición de la pobreza (más en esta última, ya que el individuo pasa de trabajar a no trabajar más que aumentar o no su salario).

\section{Conclusiones}

Usando un modelo CGE dinámico recursivo, el trabajo analiza los efectos económicos directos, indirectos, distributivos y en la pobreza de reformas que modifican la estructura tributaria chilena. Se genera un escenario base desde los años 2003 a 2025, el cual es comparado con seis simulaciones que cambian las tasas efectivas de impuestos al valor agregado e impuesto a la renta.

Las simulaciones que bajan la tasa efectiva del IVA incrementan el ingreso disponible de las familias, por lo que parte de este mayor ingreso es gastado en bienes de consumo y otra parte se ahorra. Las simulaciones que elevan el impuesto a la renta perjudican los ingresos de todos los quintiles. Al contrario, las simulaciones que bajan el IVA e incrementan la tasa efectiva del impuesto a la renta del quintil más rico de la población, elevan los ingresos disponibles de los cuatro primeros quintiles.

13 La línea de pobreza utilizada en el estudio corresponde a la que usa en Chile el Ministerio de Planificación (MIDEPLAN) actualizada al año base de la CASEN. Esta línea de pobreza se calcula en base al ingreso per cápita total del hogar. Si ese ingreso no alcanza el valor entre una y dos canastas básicas de alimentos, las personas que componen ese hogar son pobres. 


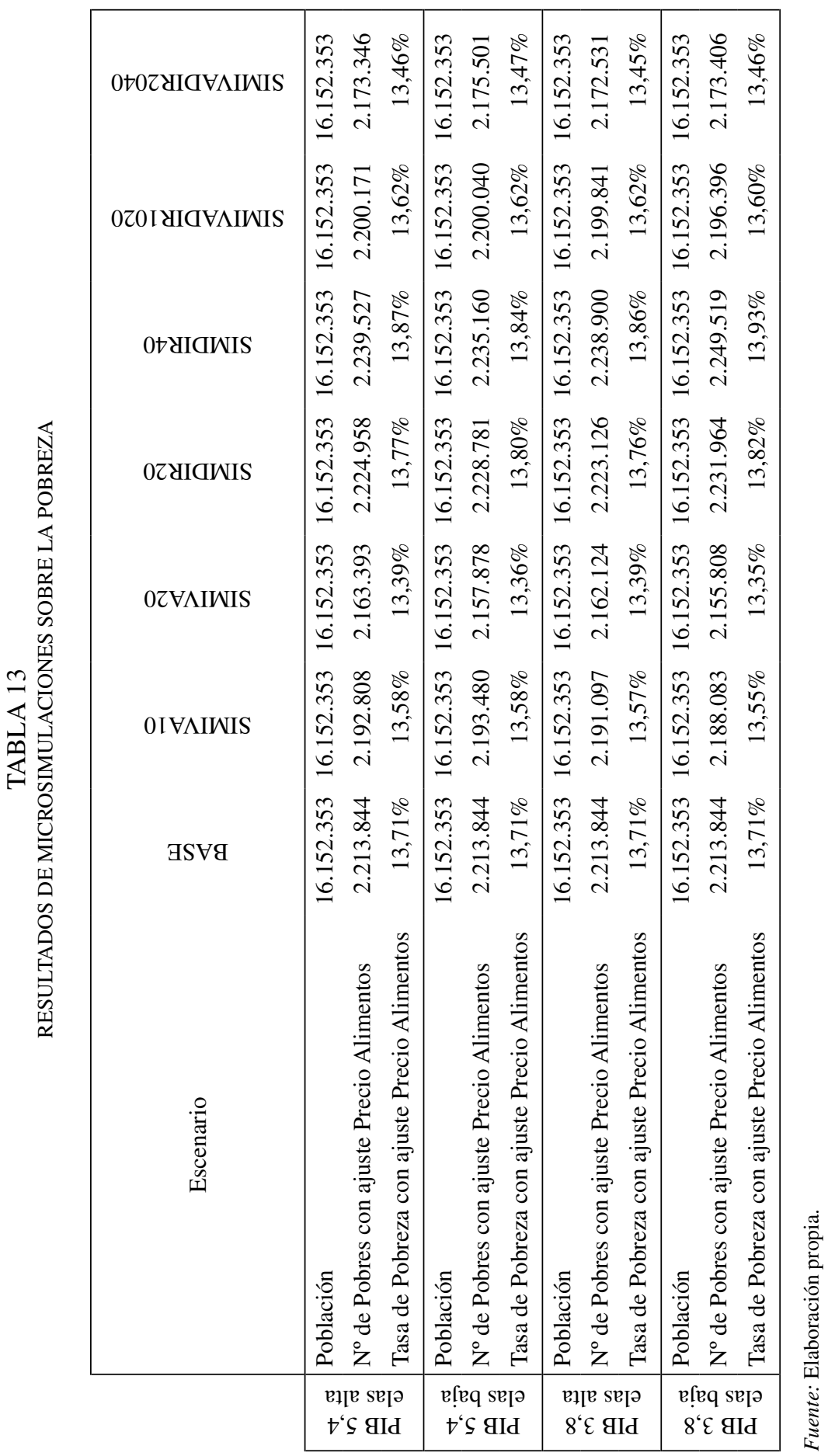


La recaudación fiscal se ve fuertemente afectada dependiendo de la reforma simulada, aunque aquellas que bajan el IVA y elevan el impuesto a la renta del quintil más rico generan un escenario muy similar al base.

A nivel sectorial se generan variaciones en la actividad producto del cambio en los precios relativos, el efecto ingreso, y las variaciones en el tipo de cambio real. Las mayores variaciones se generan en sectores exportadores y en aquellos que son más intensivamente demandados por el quintil más rico (en el caso del aumento en el impuesto a la renta).

En el mercado laboral, los resultados arrojan que en el escenario base (2003 a 2025) los salarios para los trabajadores no calificados crecen en promedio entre $3,1 \%$ y $8,6 \%$ anual, los salarios para trabajadores semicalificados entre $3,0 \%$ y $8,5 \%$, y los salarios para trabajadores calificados entre $2,7 \%$ y $8,3 \%$ (los valores más altos dependen del escenario de crecimiento alto del PIB y elasticidades bajas, mientras los valores menores dependen del escenario de crecimiento bajo del PIB y elasticidades altas). Además, al comparar con las simulaciones de reformas tributarias se concluye que aquella que reduce el IVA en $20 \%$ eleva más los salarios promedio en el horizonte modelado con respecto al escenario base, en especial se incrementan relativamente más aquellos con menor nivel de calificación (una tasa de crecimiento promedio anual entre 3,1\% y 8,7\%). Los escenarios que bajan el IVA pero elevan el impuesto a la renta también incrementan los salarios, pero con un impacto menor y más parejo entre niveles de calificación respecto al escenario base $(3,1 \%$ y $8,6 \%)$.

Por otra parte, los impactos de equilibrio general obtenidos en el mercado del trabajo y traspasados a microdatos muestran una mejora marginal en la distribución del ingreso. Concluyendo que estas reformas tributarias tienen acotado espacio para modificar la distribución del ingreso de las familias, aun cuando consideremos los efectos de equilibrio general de tales reformas. Sin embargo, estos resultados se basan en la utilización de la aplicación de una tasa impositiva promedio por decil y no de reglas impositivas detalladas para cada individuo. En consecuencia, al no considerar incentivos al ahorro en el sistema financiero, exenciones tributarias y evasión los cuales pueden afectar significativamente la carga tributaria entre personas (dependientes e independientes) y entre ingresos (laborales e ingresos de capital), así como también al tratar todos los ingresos como si fueran de una misma fuente en el modelo y en las microsimulaciones, existen limitaciones metodológicas importantes sobre los efectos en la distribución del ingreso.

Finalmente, se analiza con los microdatos contrafactuales el efecto en la pobreza de estas reformas tributarias. En términos metodológicos se incluye el efecto sobre los precios de la canasta básica de la línea de la pobreza y las variaciones en los ingresos de las familias, incremento en las remuneraciones por nivel de calificación de la mano de obra. Se concluye de los resultados que las reformas que bajan el IVA son aquellas que ayudan a reducir más la tasa de pobreza (de $13,71 \%$ a $13,39 \%$ con una rebaja de $20 \%$ en el IVA), pero que la reforma que baja el IVA y sube el impuesto a la renta del quintil más rico también genera una reducción en la pobreza relevante, mientras que las reformas que suben el impuesto a la renta elevan la tasa de pobreza (recordar que el aumento del impuesto a la renta no se redistribuye a los más pobres en la simulación lo cual condiciona el resultado). Sin embargo, estos resultados están condicionados al asumir que la oferta laboral es exógena. 
A partir de todos los resultados anteriores es posible afirmar que reformas que bajen el IVA y eleven el impuesto a la renta del quintil más rico de la población tienen la ventaja de elevar los salarios de los distintos niveles de calificación en forma homogénea, elevar los ingresos disponibles de los cuatro primeros quintiles, mantienen el balance fiscal relativamente constante, y pueden ayudar a reducir en forma acotada la desigualdad y pobreza. Además aumentan (disminuyen) las exportaciones (importaciones) levemente sobre el escenario base por el incremento marginal del tipo de cambio real, mientras en términos sectoriales aumenta levemente la actividad de los sectores agropecuario, madera, pesca, petróleo, resto de minería, manufacturero, electricidad-gas-agua y comercio, y disminuye la actividad de los sectores construcción, transporte y telecomunicaciones, servicios, servicios públicos y cobre.

\section{REFERENCIAS}

Agostini, C. (2008). “Los Impuestos Importan”, Observatorio Económico № 22, Universidad Alberto Hurtado, septiembre 2008.

Agostini, C. and I. Jalile. (2009). "Efectos de los impuestos corporativos en la inversión extranjera en América Latina". Latin American Research Review, Vol. 44. № 2: 84-108.

Aiyagari, S. Rao. (1995). "Optimal Capital Income Taxation with Incomplete Markets, Borrowing Constraints, and Constant Discounting”, Journal of Political Economy, 103 (6): 1158-1175.

Armington, P. (1969). "A Theory of Demand for Products Distinguished by Place of Production", IMF Staff Papers, 159-77.

Auerbach, A., L. Kotlikoff and J. Skinner. (1983). "The Efficiency Gains from Dynamic Tax Reform", International Economic Review, 24, 81-100.

Barra, P. y M. Jorrat. (1999). "Estimación de la Evasión Tributaria en Chile", Departamento de Estudios, Servicio de Impuestos Internos.

Benavente, J. M., J. de Gregorio y M. Núñez. (2006). "Rates of Return for Industrial R\&D in Chile”. Documento de Trabajo, 220. Departamento de Economía. Universidad de Chile, septiembre.

Besley, T. and H. Rosen. (1999). "Sales Taxes and Prices: An Empirical Analysis", National Tax Journal, Vol. 52, № 2 (June 1999), pp. 157-178.

Bourguignon, F. and A. Spadaro. (2006). "Microsimulation as a tool for evaluating redistribution policies", Journal of Economic Inequality, Springer, Vol. 4 (1), pp. 77-106, April.

Brooke, A., D. Kendrick, A. Meeraus and R. Raman. (1998). GAMS: A User's Guide. GAMS Development Corporation.

Cantallopts, J., M. Jorratt and D. Scherman. (2007). "Equidad Tributaria en Chile: Un Nuevo Modelo para Evaluar Alternativas de Reforma”, mimeo.

Claro, S. (2003). "A Cross-Country Estimation of the Elasticity of Substitution Between Labor and Capital in Manufacturing Industries". Cuadernos de Economía, Año 40, No 120, pp. 239-257.

Cok, M., B. Majcen, M. Verbic and M. Kosak. (2008). "Use of Simulation Models for the Tax Reform in Slovenia", Financial Theory and Practice, Institute of Public Finance, Vol. 32 (1), pp. 29-43. 
Conesa, J. C., and D. Krueger. (2006). "On the Optimal Progressivity of the Income Tax Code", Journal of Monetary Economics, 53 (7): 1425-1450.

Conesa, J. C., S. Kitao and D. Krueger. (2009). “Taxing Capital? Not a Bad Idea after All!", American Economic Review, American Economic Association, Vol. 99 (1), pp. 25-48, March.

Chamley, C. (1986). "Optimal Taxation of Capital Income in General Equilibrium with Infinite Lives", Econometrica, Econometric Society, vol. 54(3), pp. 607-22, May.

Chari, V., L. Christiano, and P. Kehoe. (1994). "Optimal Fiscal Policy in a Business Cycle Model”, Journal of Political Economy 102 (4), 617-652.

Devarajan, S., S. Jitsuchon and C. Sussangkarn. (1991). "A Value Added Tax (VAT) in Thailand: Who Wins and Who Loses?", TDRI Quarterly Review, Vol. 6, $\mathrm{N}^{\mathrm{o}} 1$.

Devarajan, S. and S. Robinson. (2005). "The influence of Computable General Equilibrium Models on Policy", en Frontiers in Applied General Equilibrium Modeling (ed. por T. J. Kehoe, T. N. Srinivasan y J. Whalley), pp. 402428, Cambridge University Press, Cambridge, Mass.

Diamond, P. and J. Mirrlees. (1971b). "Optimal Taxation and Public Production II: Tax Rules”, American Economic Review, American Economic Association, Vol. 61(3), pp. 261-78, June.

Diamond, P. and J. Mirrlees. (1971a). "Optimal Taxation and Public Production: I--Production Efficiency”, American Economic Review, American Economic Association, Vol. 61 (1), pp. 8-27, March.

Engel, E., A. Galetovic and C. Raddatz. (1999) "Taxes and Income Distribution in Chile: Some Unpleasant Redistributive Arithmetic", Journal of Development Economics, 59 (1), 155-192.

Field, A. and U. Wongwatanasin. (2007). "Tax policies' impact on output, trade and income in Thailand", Journal of Policy Modeling, Volume 29, Issue 3, May-June 2007, pp. 361-380.

Fontaine, B. y R. Vergara. (1997). "Una Reforma Tributaria para el Crecimiento", Estudios Públicos, 67.

Fullerton, D., J. Shoven and J. Whalley. (1983). "Replacing the U.S. Income Tax with a Progresive Consumption Tax. A Sequenced General Equilibrium Approach", Journal of Public Economics, 20, 3-23.

Ganuza, E., S. Morley, S. Robinson and R.P. Vos. (2005). “Are Export Promotion and Trade Liberalization Good for Latin America's Poor? A Comparative Macro-Micro CGE Analysis", Development Policy Review 23(3): pp. 385-403.

Gooroochurn, N. and C. Milner. (2005). "Assessing Indirect Tax Reform in a Tourism-Dependent Developing Country”, World Development, Volume 33, Issue 7, July 2005, pp. 1183-1200.

Harberger, Arnold C. (1962). "The Incidence of the Corporation Income Tax", Journal of Political Economy 70 (3): 215-240.

Harrison, G., T. Rutherford and D. Tarr. (2002). "Trade Policy Options for Chile: The Importance of Market Access", The World Bank Economic Review, Vol. 16, No 1 (2002), pp. 49-79.

Hubbard, G. and K. Judd. (1986). "Liquidity Constraints, Fiscal Policy, and Consumption", Brookings Papers on Economic Activity, 1986 (1): $1-50$. 
Imrohoroglu, S. (1998). “A Quantitative Analysis of Capital Income Taxation”, International Economic Review, 39(2): 307-328.

Jaramillo, C. y J. Tovar. (2009). "Incidencia del impuesto al valor agregado en los precios en Colombia”, El Trimestre Económico, Fondo de Cultura Económica, Vol. 0 (303), pp. 721-749, julio-sep.

Johansen, L. (1960). “A Multisectoral Study of Economic Growth”, Amsterdam: North-Holland.

Jorgenson, D. and P. Wilcoxen. (1997). "The long-run dynamics of fundamental tax reform”, American Economic Review, Vol. 87, Iss. 2; pp. 126-132.

Jones, L., R. Manuelli and P. Rossi. (1997). "On the Optimal Taxation of Capital Income", Journal of Economic Theory, 73 (1): 93-117.

Judd, K. (1985). "Redistributive Taxation in a Simple Perfect Foresight Model", Journal of Public Economics, 28 (1): 59-83.

Judd, K. (1999). "Optimal taxation and spending in general competitive growth models", Journal of Public Economics, Elsevier, Vol. 71(1), pp. 1-26, January.

Jung, H. and E. Thorbecke. (2003). "The impact of public education expenditure on human capital, growth, and poverty in Tanzania and Zambia: a general equilibrium approach", Journal of Policy Modeling, Volume 25, Issue 8, November 2003, pp. 701-725.

Lagos, C. y C. De Miguel. (2003). "Una Matriz de Contabilidad Social para Chile 1996: Diseño y Metodología”, Documento de Trabajo. Instituto de Asuntos Públicos. Universidad de Chile.

Kehoe, T. J., T. N. Srinivasan and J. Whalley. (2005). Editors for: Frontiers in Applied General Equilibrium Modeling. Cambridge University Press 2005.

Lofgren, H. and C. Díaz-Bonilla. (2009). "MAMS: An Economy-wide Model for Analysis of MDG Country Strategies -an application to Latin America and the Caribbean", Forthcoming as chapter 3 of a volume on Public Policies for Human Development. Feasible Financing Strategies for Achieving the MDGs in Latin America and the Caribbean, edited by R. Vos, E. Ganuza, H. Lofgren, M. Sánchez, and C. Díaz-Bonilla.

Lofgren, H., S. Robinson and M. El-Said. (2003). "Poverty and Inequality Analysis in a General Equilibrium Framework: The Representative Household Approach". En Bourguignon and Pereira da Silva (eds.). The Impact of Economic Policies on Poverty and Income Distribution: Evaluation Techniques and Tools. World Bank and Oxford University Press.

Mun-Heng T. and L. Qian. (2005). "An evaluation of the 1994 tax reform in China using a general equilibrium model", China Economic Review, Volume 16, Issue 3, 2005, pp. 246-270.

Nganou, J. (2004). "Estimating the Key Parameters of the Lesotho CGE Model", International Conference "Input-Output and General Equilibrium: Data, Modeling, and Policy Analysis”, Brussels (Belgium), September 2004.

O'Ryan, R., C. de Miguel and S. Miller. (2005). "A General Equilibrium Analysis of a Fuel Tax Increase in Chile". in Chumacero R., Schmidt-Hebbel K. General Equilibrium Models for the Chilean Economy, Banco Central de Chile.

O'Ryan, R., S. Miller and C.J. de Miguel. (2003). "A CGE Framework to Evaluate Policy Options for Reducing Air Pollution Emissions in Chile", Environment and Development Economics 8 (2): 285-309. 
Paulus, A. and A. Peichl. (2009). "Effects of flat tax reforms in Western Europe", Journal of Policy Modeling, Elsevier, Vol. 31 (5), pp. 620-636, September.

Poterba, J. (1996). "Retail Price Reactions a Changes in State and Local Sales Taxes", National Tax Journal. Vol. 49, No 2 (June 1996), pp. 165-76.

Radulescu, D. and M. Stimmelmayr. (2010). " The impact of the 2008 German corporate tax reform: A dynamic CGE analysis", Economic Modelling, Volume 27, Issue 1, January 2010, pp. 454-467.

Ramsey, F. (1927). "A Contribution to the Theory of Taxation", Economic Journal, 47-61.

Robinson, S., A. Cattaneo and M. El-Said. (2001). "Updating and Estimating a Social Accounting Matrix Using Cross Entropy Methods”. Economic Systems Research, Vol. 13, No 1, pp. 47-64.

Sánchez, M. (2004). "Rising Inequality and Falling Poverty in Costa Rica's Agriculture During Trade Reform. A Macro-Micro General Equilibrium Analysis, Mastricht: Shaker.

Serra, P. (2000). "Fundamentos para una Reforma Tributaria en Chile", 2000, Cuadernos de Economía 37: 299-322.

Serra, P. (2006). "El Sistema Tributario Chileno: Diagnóstico y Propuesta de Reforma", Estudios Públicos 101.

Shoven, J. B. and J. Whalley. (1972). "A General Equilibrium Calculation of the Effects of Differential Taxation of Income from Capital in the U.S", Journal of Public Economics, Vol. 1 (3-4), pp. 281-321.

Shoven, J. B. and J. Whalley. (1973). "General Equilibrium with Taxes: A Computational Procedure and an Existence Proof", Review of Economic Studies, Vol. 40 (4), pp. 475-89.

Vergara, R. (2005). "Productividad en Chile: Determinantes y Desempeño", Estudios Públicos № 99, Invierno 2005. 